\title{
Outcomes of Ultra-Fast (3 s) Photo-Cure in a RAFT- Modified Resin-Composite
}

DOI:

10.1016/j.dental.2020.02.007

Document Version

Accepted author manuscript

Link to publication record in Manchester Research Explorer

\section{Citation for published version (APA):}

Ilie, N., \& WATTS, D. C. (2020). Outcomes of Ultra-Fast (3 s) Photo-Cure in a RAFT-Modified Resin-Composite. Dental Materials, 36(4), 570-579. https://doi.org/10.1016/j.dental.2020.02.007

\section{Published in:}

Dental Materials

\section{Citing this paper}

Please note that where the full-text provided on Manchester Research Explorer is the Author Accepted Manuscript or Proof version this may differ from the final Published version. If citing, it is advised that you check and use the publisher's definitive version.

\section{General rights}

Copyright and moral rights for the publications made accessible in the Research Explorer are retained by the authors and/or other copyright owners and it is a condition of accessing publications that users recognise and abide by the legal requirements associated with these rights.

\section{Takedown policy}

If you believe that this document breaches copyright please refer to the University of Manchester's Takedown Procedures [http://man.ac.uk/04Y6Bo] or contact uml.scholarlycommunications@manchester.ac.uk providing relevant details, so we can investigate your claim.

\section{OPEN ACCESS}




\section{Outcomes of Ultra-Fast (3 s) Photo-Cure in a RAFT-Modified Resin-Composite}

Nicoleta Ilie $^{1 *}$ and David C Watts ${ }^{2}$

${ }^{1}$ Department of Conservative Dentistry and Periodontology, University Hospital, LMU Munich, Germany

${ }^{2}$ School of Medical Sciences and Photon Science Institute, University of Manchester, UK

\section{*Corresponding author:}

Prof. Dr. Dipl. Eng. Nicoleta Ilie

Department of Conservative Dentistry and Periodontology, University Hospital, LMU Munich Goethestr. 70, D-80336 Munich, Germany

Phone: +49-89-44005-9412

Fax: +49-89-44005-9302

e-mail: nilie@dent.med.uni-muenchen.de

Running title: 3-s curing 


\section{Highlights}

1. Effective photo-curing for $3 \mathrm{~s}$ at high radiant emittance is connected to a modification of the polymerization mechanism in a dimethacrylate resin-based composite (RBC) by incorporation of a RAFT (reversible addition-fragmentation chain transfer) polymerization agent.

2. RAFT and free radical polymerisation result in comparable RBCs properties. Small differences are evidenced as a slightly faster initial polymerisation kinetic in the RAFT system, while DC measured 300 s post irradiation remained similar.

3. Effective curing for $3 \mathrm{~s}$ at high irradiance is possible, but clinical tolerance should be limited to an exposure distance of 5-mm while angulation should be avoided. 


\begin{abstract}
Objective: This study evaluates critical material properties resulting from ultra-fast ( $3 \mathrm{~s})$ photo-polymerization at high radiant emittance of a pre-production, novel bulk-fill resinbased composite (RBC) modified for reversible addition-fragmentation chain transfer (RAFT) polymerization.
\end{abstract}

Methods: The output characteristics of the associated light curing unit (LCU) were measured on a laboratory-grade spectrometer. Real-time Fourier Transform Infrared Spectroscopy (FTIR) and mechanical investigations (depth-sensing indentation with a linear and spatial distribution of the measured properties, and three-point bend tests) were performed using, as reference material, an established bulk-fill RBC of comparable chemical composition. Micromechanical properties were mapped to quantify material tolerance to sub-optimal_,but elinically relevant curing conditions (exposure distance of $5 \mathrm{~mm}$ and an angulation of the $\underline{\mathrm{LCU}}$ of $20^{\circ}$ and $\left.30^{\circ}\right) \mathrm{vs}$. ideal curing conditions (exposure distance of $0 \mathrm{~mm}$ and no angulation), with 3 s polymerization. Weibull statistics, one- and multiple-way analysis of variance (ANOVA) and the Tukey honestly significant difference (HSD) post hoc-test ( $\alpha$ $=0.05)$ were used for data comparison.

Results: The change in cure mechanism to RAFT polymerisation gave slightly faster initial polymerisation kinetics, but DC measured $300 \mathrm{~s}$ post irradiation was similar, irrespective of material, curing depth or polymerisation condition. Slightly better polymerisation, in layers thicker than 4-mm, was identified in the RAFT polymerised RBC. However, slightly lower flexural modulus and hardness, up to $1.5-\mathrm{mm}$ subsurface, were related to the $c a$. one wt.\% lower inorganic filler content.

Significance: RAFT polymerisation induced comparable properties to a RBC cured via free radical polymerisation of comparable chemical composition. The RAFT polymerised RBC with high irradiance for $3 \mathrm{~s}$ was equivalent to $10 \mathrm{~s}$ of moderate irradiance. However, the clinical tolerance for $3 \mathrm{~s}$ irradiance should be limited to an exposure distance of 5-mm and angulation of the LCU should be avoided. If this is not possible, an additional $3 \mathrm{~s}$ polymerisation is recommended.

Keywords: resin-based composite, RAFT-polymerization, fast-curing, degree of cure, polymerisation kinetics, $\underline{\text { b} B u l k--f i l l . ~}$ 


\section{Introduction}

For several decades, many clinician groups have wished for shorter irradiation times when photocuring dental resin-based composite (RBC) restorations. For some time, manufacturers primarily addressed this request by increasing the radiant emittance of light curing units (LCUs). This included development of plasma arc LCUs for dentistry with radiant emittance near 2,000 $\mathrm{mW} / \mathrm{cm}^{2}$ [1]. These plasma LCUs were advocated for rapid, 3-second curing, as being equivalent to that of 40 or $60 \mathrm{~s}$ exposures from a QTH (Quartz Tungsten Halogen) light [1]. This concept failed, given that subsequent studies clearly attested insufficient polymerization $[1,2]$ and emphasized the need for multiple 3-s exposures to achieve a clinically adequate performance [1,3].

Associated with these approaches was the concept of "exposure reciprocity": that one could deliver the required photon-dose over a shorter irradiation period by significantly increasing the light irradiance (photons/second). This concept has proved controversial over the past 20 years and has been dismissed as unworkable [4,5]. However, many of the earlier studies were on resin-composites incorporating Norrish Type II photoinitiators, principally camphorquinone (CQ)/Amine. More recently, the Stansbury-Bowman group has established that, for mechanistic reasons, exposure reciprocity may be achievable using Norrish Type I photoinitiators [6]. Very recently, a NIST group has established empirically that, within appropriate ranges of irradiance and resin-composite viscosity, conditions may be met for valid exposure reciprocity [7]. Although this evidence is empirical it has been known for some time that system viscosity has a significant influence by reducing the rate of free-radical termination reactions.

The use of LCUs with high radiant emittance raised, in addition, concerns for: (i) potential injury of the pulp and soft tissues by development of high temperatures [8] plus (ii) the accumulation of residual stresses in the polymerized material. This second aspect has been demonstrated at both the macroscopic [9] and molecular [10] scales. The latter has been interpreted as due to greater chain segment extension at fast polymerization rates creating residual stress via reduced structural order and free volume [10].

Technological progress in the development of high power LED (light emitting diode) chips [1] has enabled progressively higher radiant emittance (up to $3,000-7,000 \mathrm{~mW} / \mathrm{cm}^{2}$ ) in modern LED LCUs [11]. However, an attempt to achieve adequate cure of methacrylatebased RBCs with 1 to $3 \mathrm{~s}$ irradiation was restated, but then again failed [11].

A major reduction in curing time (to $3 \mathrm{~s}$ ) in methacrylate-based RBCs was achieved only when conventional Norrish Type II photo-initiators (CQ/Amine) were replaced by Norrish Type I photoinitiators (e.g. monoacylphosphine oxide Lucirin-TPO) used at appropriate curing conditions (radiant emittance $>500 \mathrm{~mW} / \mathrm{cm}^{2}$, wavelength range 395-415nm) [12]. However, this approach has not yet been implemented in commercial RBCs, since a change in the output spectrum of LED-LCUs would have been necessary. 
Recently, a new approach has been proposed to reduce the curing time of RBCs. It connects curing, with high radiant emittance, to a modification of the polymerization mechanism in a specific dimethacrylate-based RBC: Tetric PowerFill (Ivoclar Vivadent AG). This RBC incorporate a reversible addition-fragmentation chain transfer (RAFT) polymerization mechanism. $3 \mathrm{~s}$ - irradiation is proposed for a bulk-fill application. This means that the bulkfill RBC needs to be adequately cured in increments of at least $4 \mathrm{~mm}$. RAFT polymerization has been previously incorporated in a bulk-fill RBC (Filtek One Bulk Fill, 3M). That material was designed to have improved depth of cure combined with reduced translucency to achieve improved esthetic appearance $[13,14]$

It was therefore the aim of the present study to assess the outcomes of fast curing $(3 \mathrm{~s})$, with high radiant emittance, on the polymerization process and mechanical properties of an experimental bulk-fill RBC modified to incorporate RAFT polymerization. In addition, the tolerance of this RBC to improper curing conditions was to be quantified, including increased exposure distance and/or angulation of the LCU, as may occur clinically, when access to a restoration is obstructed. A prototype LCU, designed for fast curing with high radiance emittance, was used and characterized.

The null hypotheses tested were that:

a) For a RAFT polymerized bulk-fill RBC, fast $3 \mathrm{~s}$ curing with high irradiance (curing mode flash) is not significantly different to curing for $10 \mathrm{~s}$ (mode high, $10 \mathrm{~s}$ ) in terms of polymerisation kinetics, degree of conversion (DC), various macro and micro-mechanical properties, and with increase of exposure distance and LCU angulation during curing;

b) Under identical curing conditions, the RAFT-polymerised bulk-fill RBC shows no significant differences in polymerisation kinetics, DC and micro-mechanical properties, for each analysed specimen depth, from those exhibited by an established, regular bulk-fill RBC of comparable chemical composition cured by conventional free radical polymerization. 


\section{Materials and Methods}

An experimental bulk-fill RBC modified for RAFT polymerization (F-Composit 2, Abb. FC2; IV A, LOT W92823, Ivoclar Vivadent, Schaan, Liechtenstein; current commercial name Tetric PowerFill) was analysed in relation to an already established bulk-fill RBC (Tetric EvoCeram Bulk Fill, Abb. TEVO-BF, IV A, LOT X24046, Ivoclar Vivadent, Schaan, Liechtenstein).

A Prototype LCU (Ivoclar Vivadent, Schaan, Liechtenstein, SN: 1428000006, current commercial name Bluephase Power Cure) was used for polymerization in two different curing modes (flash for $3 \mathrm{~s}$ and high for $10 \mathrm{~s}$ ).

The curing characteristics of this LCU (radiant emittance, radiant exposure and spectral distribution) were determined for both curing modes as a function of exposure distance. Degree of conversion and polymerisation kinetics parameters of the above-described RBCs were assessed in real-time for five min at two clinical relevant increment thicknesses (2-mm and 4-mm). The variation in micro-mechanical properties, measured in $100-\mu \mathrm{m}$ steps in a line profile along 6-mm high specimens pre-stored in water at $37^{\circ} \mathrm{C}$ for $24 \mathrm{~h}$, was used to calculate the depth of cure (DOC). The spatial distribution of the micro-mechanical parameters (Vickers hardness and indentation modulus) was recorded in 500- $\mu \mathrm{m}$ steps, in specimens cured under ideal curing conditions (LCU in proximate contact to the specimen surface) as well as in simulated, clinical relevant curing conditions (variation of exposure distance and/or LCU angulation).

\section{LCU characteristics}

The irradiance (= radiant flux or power received by a surface per unit area), radiant exposure and spectral distribution of the used LCU was measured on a laboratory-grade NISTreferenced USB4000 Spectrometer (MARC-RC (Managing Accurate Resin Curing) System, Bluelight Analytics Inc., Halifax, Canada). The exposure distance was varied from 0 to 10 $\mathrm{mm}$, in 1-mm steps, while the LCU was centered relative to the sensor. The diameter of the LCU light guide was $9 \mathrm{~mm}$ while the diameter of the sensor was $3.9 \mathrm{~mm}$. Radiant emittance was measured under simulated, ideal or clinical relevant curing conditions, by varying the exposure distance $(0-\mathrm{mm}, 5-\mathrm{mm})$ and/or LCU angulation $\left(0^{\circ}, 20^{\circ}\right.$ and $\left.30^{\circ}\right)$.

The miniature fiber optic Spectrometer uses a 3648-element Toshiba linear CCD array detector and high-speed electronics. The spectrometer was spectro-radiometrically calibrated with Ocean Optics' NIST-traceable light source (300-1050 nm). The system uses a CC3-UV Cosine Corrector to collect radiation over $180^{\circ}$ field of view thus mitigating the effects of optical interference associated with the light collection sampling geometry. Irradiance over a wavelength range of $360-540 \mathrm{~nm}$ was collected at a rate of 16 records/s on five occasions. The sensor was triggered at $20 \mathrm{~mW}$. 


\section{Degree of conversion (DC)}

DC was measured using Fourier Transform Infrared (FTIR) spectroscopy with an FTIRSpectrometer fitted with an attenuated total reflectance (ATR) accessory (Nicolet iS50, Thermo Fisher, Madison, USA). Spectra were measured with a resolution of $4 \mathrm{~cm}^{-1}$, in realtime over 5 min taking one spectrum each $0.4 \mathrm{~s}$ using two distinct specimen geometries: at specimen depths of 2 and $4 \mathrm{~mm}$. White, opaque, Teflon specimen molds ( $3 \mathrm{~mm}$ diameter, 2 and 4-mm thick) were filled in bulk with the RBCs under investigation.

For each of the investigated groups (two specimen depths, two RBCs and two curing modes), 6 specimens were employed to determine DC. The non-polymerized material was applied directly onto the diamond ATR crystal in the respective molds and covered with a transparent matrix strip. TEVO-BF was irradiated for $10 \mathrm{~s}$ in the LCU high curing mode, while the experimental RBC was either light irradiated for $10 \mathrm{~s}$ (high) or $3 \mathrm{~s}$ (flash). DC was calculated by computing the variation in peak height ratio of the absorbance intensities of methacrylate carbon to carbon $(\mathrm{C}=\mathrm{C})$ double bond peak at $1634 \mathrm{~cm}^{-1}$ by employing the aromatic $\mathrm{C}=\mathrm{C}$ double bond peak at $1608 \mathrm{~cm}^{-1}$ as an internal standard during polymerization of the uncured material using Equation 1:

$$
\mathrm{DC}_{\text {Peak }} \%=\left[1-\frac{\left(1634 \mathrm{~cm}^{-1} / 1608 \mathrm{~cm}^{-1}\right)_{\text {Peak height after curing }}}{\left(1634 \mathrm{~cm}^{-1} / 1608 \mathrm{~cm}^{-1}\right)_{\text {Peak height before curing }}}\right] \times 100 \quad \text { Equation } 1
$$

For each material, the increase in DC was mathematically modelled by the superposition of two exponential functions where the overall function was represented by the sum of two exponential functions as outlined in Equation 2.

$$
y=a *\left(1-e^{-b x}\right)+c *\left(1-e^{-d x}\right)
$$

Equation 2

where the parameters $\mathrm{a}, \mathrm{b}, \mathrm{c}, \mathrm{d}$ were the modulation factors of the exponential function to optimise the fit of the double exponential function on the measured curve plotted as a DC versus time curve.

\section{Flexural strength (FS) and flexural modulus (FM)}

The flexural strength and flexural modulus were determined in a three-point-bending test $(\mathrm{n}=$ 20) in accordance with ISO 4049:2009. Therefore, 20 samples for TEVO-BF (10 s, high) and 40 samples for FC2 (10 s, high and $3 \mathrm{~s}$, flash) were made by compressing the material between two glass plates with intermediate polyacetate sheets, separated by a Teflon mold having an internal dimension of $(2 \times 2 \times 18) \mathrm{mm}$. Specimens were removed from the mold and then stored in distilled water at $37^{\circ} \mathrm{C}$ prior to testing for $24 \mathrm{~h}$. The specimens were loaded until failure in a universal testing machine (Z 2.5, Zwick/Roell, Ulm, Germany). The crosshead speed was $0.5 \mathrm{~mm} / \mathrm{min}$. The three-point bending test device was constructed according to the guidelines of NIST No. 4877 with $12 \mathrm{~mm}$ distance between the supports. During testing the specimens were immersed in distilled water at room temperature. 


\section{Micro-mechanical properties profiles and depth of cure}

Cylindrical specimens $(\mathrm{n}=6$, height $=6 \mathrm{~mm}$, diameter $=10 \mathrm{~mm})$ were prepared in cylindrical metal mouldmolds. TEVO-BF specimens were cured for $10 \mathrm{~s}$ in curing mode high by applying the LCU perpendicular, directly on the top surface of the cylinder. FC2 specimens were cured either for $10 \mathrm{~s}$ in curing mode high or for $3 \mathrm{~s}$ in mode flash. Specimens were then removed from the mouldmold and stored in $37^{\circ} \mathrm{C}$ distilled water for $24 \mathrm{~h}$. Prior to measurement, specimens were sectioned in the middle, parallel to the direction of curing, with a slow-speed diamond saw (Isomet low-speed saw, Buehler, Germany) under water cooling. Each sample was then fixed to a glass slide, mounted in an automatic grinding machine (EXAKT 400CS Micro Grinding System, EXAKT Technologies, Inc. OK, USA), wet-ground with silicon carbide sand paper (grit size p2500 and p4000, LECO Corporation, USA) and polished with a diamond suspension (Struers GmbH, Willich, Germany; mean grain size: $1 \mu \mathrm{m})$.

Measurements were made with an automatic micro hardness indenter (Fischerscope H100C, Fischer, Sindelfingen, Germany) in the middle of the specimens, starting at $0.1 \mathrm{~mm}$ under the surface, with $100-\mu \mathrm{m}$ intervals between the measuring points, summarising 360 single indentations for each curing condition and material.

The test procedure was carried out force-controlled, where the test load increased and decreased with constant speed between $0.4 \mathrm{mN}$ and $500 \mathrm{mN}$. Load and penetration depth of the indenter were continuously measured during the load-unload hysteresis. Universal hardness is defined as the test force divided by the apparent area of indentation under applied test force. From a multiplicity of measurements stored in a database supplied by the manufacturer, a conversion factor between Universal hardness and Vickers hardness (HV) was calculated and input into the software. Indentation modulus ( $\left.\mathrm{Y}_{\mathrm{HU}}\right)$ was calculated from the slope of the tangent of the indentation depth curve at maximum force. Hardness and indentation modulus variation with depth were calculated for each group based on data from six samples.

The depth of cure (DOC), is usually acknowledged as the thickness of a RBC that is adequately cured or rather as the depth where HV equals the surface value multiplied by an arbitrary ratio, usually 0.8 [15] (= HV-80 \%). Therefore, for each specimen, HV at each depth was compared to the $0.1 \mathrm{~mm}$ subsurface value, and noted when it became less than $80 \%$. This depth was indicated as DOC.

Further, to analyse statistically the variation in micro-mechanical properties at different depths, data recorded within each $0.5 \mathrm{~mm}$ depth interval were grouped together.

\section{Spatial distribution of the micro-mechanical parameters}

The spatial distribution of the micro-mechanical parameters (hardness and indentation modulus) was assessed on specimens of similar geometry as described above $(n=3)$, cured at an exposure distance of either $0 \mathrm{~mm}$ or $5 \mathrm{~mm}$ while the LCU was placed either perpendicular 
or at angles of $20^{\circ}$ and $30^{\circ}$ to the surface. Aging, surface preparation and indentation conditions were similar as above, while mapping was performed with $0.5 \mathrm{~mm}$ distances between indentations, within a $(6 \times 6) \mathrm{mm}^{2}$ central area of the cylindrical specimens with a height of $6 \mathrm{~mm}$ and a diameter of $10 \mathrm{~mm}$.

\section{Statistical analyses}

A Shapiro-Wilk test verified the normal distribution of the data. The results were compared using one- and multiple-way analysis of variance (ANOVA) and Tukey honestly significant difference (HSD) post hoc-test $(\alpha=0.05$ ) when using SPSS Inc. (Version 25.0, Chicago, IL, USA). A multivariate analysis (general linear model) assessed the effect of various parameters as well as their interaction terms on DC, micro-mechanical properties as well as flexural strength and flexural modulus. The partial eta-squared statistic reported the practical significance of each term, based on the ratio of the variation attributed to the effect. Larger values of partial eta-squared $\left(\eta \mathrm{p}^{2}\right)$ indicate a greater amount of variation accounted for by the model, which add up to a maximum of 1.0. A Weibull analysis was performed for the flexural strength data. 


\section{Results}

The analyzed LCU was evidenced as a violet-blue LED-LCU with two peaks located at 412 $\mathrm{nm}$ and $455 \mathrm{~nm}$ (Fig 1). For the high curing mode, the irradiance varied from 1,515.3 $( \pm 11.01) \mathrm{mW} / \mathrm{cm}^{2}$, at an exposure distance of $0-\mathrm{mm}$, down to $1,083.3( \pm 21.03) \mathrm{mW} / \mathrm{cm}^{2}$, at an exposure distance of $5 \mathrm{~mm}$, and $500.7( \pm 4.2) \mathrm{mW} / \mathrm{cm}^{2}{ }_{2}$ at an exposure distance of $10-\mathrm{mm}$ (Fig 2). For the flash mode, it varied from 3,770.3 $( \pm 35.30)$ down to $\underline{2,693.3( \pm 34.3) \mathrm{mW} / \mathrm{cm}^{2}}$ $(5-\mathrm{mm})$ and $1,176.1( \pm 7.0) \mathrm{mW} / \mathrm{cm}^{2}(10-\mathrm{mm})$. The radiant exposure (irradiance integrated over time of irradiation) was significantly lower higher in the high mode compared to flash, for both violet and blue wavelength ranges (Fig 3-a and b).

The parameters: exposure distance and LCU angulation, as well as their binary combination exerted a significant ( $\mathrm{p}<0.001$, partial eta squared $\eta_{\mathrm{P}^{2}}=0.99$ to 0.96$)$ effect on the irradiance emitted in the flash mode, while the effect of angulation was stronger at higher exposure distances (Fig 4). Related to ideal curing conditions (exposure distance $=0 \mathrm{~mm}$, angulation $=$ $0^{\circ}$ ), the radiant exposure decreased up to $63.5 \%$ (blue wavelength range) in the most unfavourable analysed curing condition (exposure distance $=5 \mathrm{~mm}$, angulation $=30^{\circ}$ ). Note that the radiant exposure was equivalent in the case of perpendicular placement of the LCU at an exposure distance of $5 \mathrm{~mm}$ and a $30^{\circ}$ angulation at zero exposure distance (Fig 5).

Fig 6 illustrates the FTIR spectra of the uncured RBCs, measured at the base of 2-mm thick specimens, while the $\mathrm{DC}_{300 \mathrm{~s}}$ values, measured $300 \mathrm{~s}$ post light irradiation as a function of material, specimen depth and curing mode are illustrated in Fig 7. A multifactorial analysis identified no influence of the above mentioned parameters (material, $\mathrm{p}=0.56$; specimen depth, $p=0.463$; curing mode, $p=0.165$ ). Similarly, an independent $t$-test revealed no significant difference within one material and curing mode between the $\mathrm{DC}_{300 \text { s }}$ measured at depths of $2 \mathrm{~mm}$ or $4 \mathrm{~mm}$.

The variation of DC versus time (Fig 8) was best described by an exponential sum function, manifested by a high correlation factor of $\mathrm{R}^{2}>0.90$ defined for the parameters $\mathrm{a}, \mathrm{b}, \mathrm{c}$, and $\mathrm{d}$. The first exponential function characterizes the gel phase (parameters " $a$ " and " $b$ ") and the second the glass phase (parameters "c" and "d") (Table 1).

The kinetic parameters for the $\mathrm{C}=\mathrm{C}$ double bond conversion were identical for 2 and 4-mm depths for TEVO-BF (curing mode high, $10 \mathrm{~s}$ ). For the same curing mode, a slightly faster (higher $\mathrm{a}, \mathrm{b}$ ) polymerization was identified for a depth of $2 \mathrm{~mm}$ in FC2 vs. TEVO-BF. The kinetic parameters of both materials were similar for a depth of $4 \mathrm{~mm}$.

With FC2, fast curing (flash, $3 \mathrm{~s}$ ) gave higher "b" parameters compared to curing for $10 \mathrm{~s}$ in the high mode, at both 2 and 4 mm depths. Parameter "a" (describing the gel phase) was lower at $2 \mathrm{~mm}$ depth, which was compensated by a significant higher parameter "c" (describing the glass-phase). In contrast, parameters a, c and d were similar at $4 \mathrm{~mm}$ depth, irrespective of the curing mode (Table 1). 
Flexural strength (FS) and flexural modulus (FM) measured for FC2 were similar for both curing modes (Table 2). Only the reliability was slightly higher when curing FC2 in the curing mode high for $10 \mathrm{~s}$ (Fig 9). At similar curing conditions, FC2 and TEVO-BF showed similar FS values, while the FM was slightly higher for TEVO-BF, and the reliability higher for FC2 (Table 2).

The variation in micro-mechanical properties with depth identified no effects from changing the curing conditions in the material FC2. This was confirmed by similar depths of cure (DOC; $p=0.197$ ), as summarised in Fig 10. Under identical curing conditions, FC2 revealed a slightly, but significantly, higher DOC compared to TEVO-BF $(p<0.001)$. HV was significantly higher in TEVO-BF vs. FC2 up to $1.5 \mathrm{~mm}$ depth, but, subsequently, statistical similar up to $3.5 \mathrm{~mm}$ depth and then significantly lower up to $6 \mathrm{~mm}$ depth. The indentation modulus of both materials was similar up to a depth of $3.5 \mathrm{~mm}$. Subsequently, significant higher values were recorded for FC2 (Fig 11).

Mapping the micro-mechanical properties confirmed similar results in FC2 specimens, irrespective of the curing mode (Fig S1 - see Supplementary Data). The map profiles of TEVO-BF and FC2 (Fig S2) cured under identical conditions (curing mode high, $10 \mathrm{~s}$ ) revealed similar properties at $2 \mathrm{~mm}$ depth and slightly higher properties for FC2 at $4 \mathrm{~mm}$ depth, confirming DOC data presented above. For the simulated clinically relevant curing conditions for the fast curing mode flash, data recorded under ideal curing conditions (exposure distance $=0 \mathrm{~mm}$, angulation $=0$ ) in a subsurface of $0.5 \mathrm{~mm}$ were taken as a reference. Increasing the exposure distance from $0-\mathrm{mm}$ to $5-\mathrm{mm}$ resulted in decreased micromechanical properties at a depth of $4 \mathrm{~mm}$, corresponding to $80 \%$ of the reference value for $\mathrm{HV}$, and $87 \%$ of the reference value for $\mathrm{Y}_{\mathrm{HU}}$ (Fig S3). When LCU angulation was combined with an exposure distance of $5 \mathrm{~mm}$, similar properties to the reference were identified up to a depth of $2 \mathrm{~mm}$, but the measured properties decreased with angulation in deeper layers; the greater the angulation, the greater the decrease (Fig S4). 


\section{Discussion}

The reversible addition-fragmentation chain transfer (RAFT) polymerization process is the most recent of the living/controlled free radical methodologies. It is intended to reduce the drawbacks of a free radical polymerization, which are seen in a relatively broad molecular mass distribution and the limited control over polymer architecture and end group functionality [16]. This process was introduced relatively recently into dental materials and, so far, in only two commercial bulk-fill RBCs. The most recent application and the corresponding effects on material properties are described in the present study.

RAFT polymerization is generally performed by adding an appropriate RAFT agent to a conventional free radical polymerization. The RAFT agent used in FC2 is described as a $\beta$ allyl sulfone [17], a class of substances that proved previously to be potent reagents in methacrylate systems [18]. Furthermore, the content and the functionality of these $\beta$-allyl sulfones as RAFT agent was evidenced as key agents in tuning the properties of the resultant dimethacrylate networks, allowing for improved homogeneity of the networks as well as a narrow glass transition region and an adjustable glass transition temperature and network density [18].

Usually, the same monomers, initiators, and solvents can be used in both RAFT and conventional free radical polymerization [16]. This appears to have occurred in the development of the analyzed experimental material FC2, which is based to a great extent on the commercial material TetricEvoCeram Bulk-Fill (TEVO-BF), as is also noticeable in the nearly similar FTIR spectra of both materials (Fig 6). Note that FC2 was the last experimental version, prior to launching the commercial RBC Tetric PowerFill [17] for which the manufacturer specifies a composition of the organic matrix based on Bis-GMA (Bisphenol Adiglycidyl dimethacrylate) as the main component, UDMA (urethane dimethacrylate) and Bis-EMA (Ethoxylated bisphenol A dimethacrylate). The same monomers are described also in the chemical composition of TEVO-BF [19]. Tetric PowerFill contains additionally the monomers tricyclodocane dimethanol dimethacrylate (DCP) and Propoxylated Bisphenol A dimethacrylate [17].

The RAFT polymerization process operates on the principle of reversible chain transfer, involving an additional step. The pre- and main equilibrium steps are superimposed on a conventional radical polymerization scheme [16]. The first two steps of the polymerization process - initiation and propagation - are similar in both RAFT and conventional radical polymerization [16]. Therefore, the polymerization is initiated in the same way in both analyzed materials, by light activation, which occurred in the present study by means of a violet-blue LED-LCU, using three different types of photoinitiator - (CQ)/amine, an acyl phosphine oxide (TPO) and Ivocerin (bis-(4-methoxybenzoyl)diethylgermane) [17, 19]. After the radical transfer from the initiator molecules to the monomer units, the propagation step, i.e. the increasing chain length, is described as also being similar in both processes [16]. A subsequent step occurs in a RAFT-polymerization, denoted as the RAFT pre-equilibrium 
step, in which the propagating radical reacts with the RAFT agent ( $\beta$-allyl sulfone, in the analyzed material) to form an intermediate radical (RAFT-adduct radical). This RAFT-adduct radical can then undergo a fragmentation reaction, either yielding back the reactants or releasing an initiating-leaving group radical with concomitant formation of a polymeric compound, which constitutes the dormant species [16]. The following step, the re-initiation, also applies only to the RAFT polymerization. It involves the reaction between the leaving group radical and another monomer species, allowing startup of another active polymer chain. It follows the most important part in the RAFT process, described as the main RAFT equilibrium, is which a similar set of reactions, as described in the pre-equilibrium step, is operating. Therefor a propagating macro-radical reacts with the polymeric RAFT agent. Recurring RAFT events establish the equilibrium between dormant and living chains, by which living/controlled characteristics are induced into the polymerization [16]. In the termination step, active chains react via bi-radical termination to form chains that cannot react further (dead polymer).

Within the complex processes described above, the chosen RAFT agent and implicitly the rate of the fragmentation reaction play a key role. If the overall rate of fragmentation is slow relative to propagation then retardation is a likely result [16]. If the reaction is set so that both addition and fragmentation are rapid and irreversible with respect to propagation, the polymerization kinetics differ little from those seen in polymerization with conventional chain transfer [16]. This seems to apply to FC2 (RAFT polymerization) when compared to TEVO-BF (conventional radical polymerization) under similar curing conditions (high, 10s), as evidenced by similar kinetic parameters at a depth of $4 \mathrm{~mm}$, while only slightly faster kinetics (higher parameters $a$ and $b$ ) were noted at a depth of $2 \mathrm{~mm}$ for FC2 in the same material comparison. It should be emphasized that the DC measured $300 \mathrm{~s}$ post irradiation was similar in both materials. Thus the slightly faster kinetic of FC2 in upper layers had no effect on the post-polymerization in view of the $\mathrm{C}=\mathrm{C}$ double bond conversion. Moreover, both materials proved to be adequately cured at the required 4-mm increment thickness for a bulk-fill placement, as evidenced in similar $\mathrm{DC}_{300 \text { s }}$ values at 2-mm and $4-\mathrm{mm}$ depths. This was confirmed by measurements of micro-mechanical properties collected $24 \mathrm{~h}$ postirradiation. The chosen curing condition for comparing both materials (mode high, $10 \mathrm{~s}$ ) was in line with manufacturer recommendations and proved in previous studies to be sufficient to adequately cure the material TEVO-BF.

According to the same comparison, materials exhibited similar flexural strengths, although the flexural modulus and the hardness up to $1.5 \mathrm{~mm}$ subsurface were slightly superior in TEVO-BF. This can be attributed to small differences in the inorganic filler amount, which was slightly higher in TEVO-BF (78-79 wt\% (6) vs. 76-77 wt\% in FC2 [17]). The same line of argument may explain the higher DOC in FC2 vs. TEVO-BF, since a lower filler amount will have resulted in reduced light scatter, allowing more light penetration into deeper material layers. Note, however, that DOC was higher than $4 \mathrm{~mm}$ in both materials. In addition, the spatial distribution of the measured micro-mechanical properties was comparable up to this depth. Differences between materials to the detriment of TEVO-BF are 
registered in layers deeper than $5 \mathrm{~mm}$ (Fig. S2). These were not evaluated statistically, since a bulk-fill material should not be used in increments larger than $4 \mathrm{~mm}$.

The RAFT polymerized material FC2 was designed for fast polymerization ( $3 \mathrm{~s}$ ) with high LCU irradiance. Curing via the flash mode for $3 \mathrm{~s}$ was evidently sufficient and equivalent to curing for $10 \mathrm{~s}$ in a lower irradiance mode, as reflected in similar DOC and $\mathrm{DC}_{300 \mathrm{~s}}$ values as well as macro and micro-mechanical properties. Curing with high irradiance affected solely the speed of the polymerization in the initial phase, as evidenced in higher values calculated for the parameters $a$ and $b$. The spatial distribution of the micro-mechanical properties indicated similar results for the clinically required $4 \mathrm{~mm}$ increment, but showed a superiority in deeper layers when curing with moderate irradiance for $10 \mathrm{~s}$ (high). This was, however, related to differences in radiant exposure, which for the high mode (10 s) was about 20\% higher in the blue wavelengths range and 3-fold higher in the violet wavelength range compared to the fast curing flash mode $(3 \mathrm{~s})$.

Since the evaluated flash mode involves a very short exposure time $(3 \mathrm{~s})$, small deviations from ideal curing conditions were considered to have a high impact on the curing behavior of the material FC2, particularly regarding depth-variation of properties. It should also be emphasized that reducing the curing time withby only $1 \mathrm{~s}$ amounts to a $33 \%$ reduction in radiant exposure. The spatial distribution of the micro-mechanical properties evidenced that the tolerance limit had already been reached at an exposure distance of $5 \mathrm{~mm}$ and any additional angulation of the LCU during the curing process could result in insufficient polymerization at a depth of 4-mm, even if the first 2-mm were thoroughly polymerized. The analyzed RAFT-polymerized RBC as well as the LCU represent the last version previousprior to product launching, but were tested in the present study as experimental material and LCU.

\section{Conclusions:}

Modifying the polymerisation mechanism to a RAFT polymerisation was shown to induce comparable properties to those of an $\mathrm{RBC}$ of almost equivalent material composition cured via conventional free radical polymerisation. Differences were evidenced only in faster initial polymerisation kinetics in the RAFT system while DC measured $300 \mathrm{~s}$ post irradiation was similar. The slightly better polymerisation in layers thicker than $4 \mathrm{~mm}$ as well as small differences in HV and FM were related to the ca. one wt.\% lower inorganic filler content in the RAFT polymerised material. Moreover, the RAFT polymerised material allowed curing for $3 \mathrm{~s}$ at high irradiance. The clinical tolerance should be limited to an exposure distance of 5-mm and angulation should be avoided. Where this is not possible, an additional $3 \mathrm{~s}$ polymerisation is recommended.

\section{Conflicts of Interest statement:}

The authors declare no conflict of interest. The founding sponsor had no role in the design of the study, in the collection, analyses, or interpretation of data, in the writing of the manuscript 
or in the decision to publish the results.

\section{Acknowledgements:}

The experimental work was supported to $25 \%$ by the company Ivoclar-Vivadent AG.

Author Contributions: NI conceived and designed the experiments and methods, performed the experiments, collected, presented and analysed the data, performed statistics, wrote the paper. DCW discussed the interpretation of results, added additional references and participated in writing the final manuscript. 


\section{Figures and tables caption:}

\section{Tables:}

Table 1: Polymerisation kinetic parameters: $95 \%$ confidence interval of the modulation factors of the exponential function $(\mathrm{a}, \mathrm{b}, \mathrm{c}, \mathrm{d})$ and correlation factor $\left(\mathrm{R}^{2}\right)$.

Table 2: Descriptive statistic (mean and standard deviation) for the flexural strength (FS, $\mathrm{MPa}$ ) and modulus (FM, GPa) as a function of material and curing mode. Superscripts indicate statistically homogeneous subgroups within a line (Tukey's HSD test, $\alpha=0.05$ ). Weibull parameters with the $95 \%$ confidence interval of the Weibull modulus $m$ are indicated.

\section{Figures:}

Figure 1: Spectral emission of the LED prototype light-curing unit measured in the modes: flash (red) and high (blue). Note that the spectral emission in the violet wavelength range is similar for both output modes.

Figure 2: Variation in irradiance with exposure distance and curing mode.

Figure 3: Variation in radiant exposure with exposure distance and curing mode for a) the blue wavelength range and $b$ ) the violet wavelength range.

Figure 4: Variation in irradiance with exposure distance and angulation (flash mode).

Figure 5: Percentage decrease in radiant exposure (RE) at simulated clinical relevant curing conditions in relation to the maximum RE-value, reached at ideal curing conditions (exposure distance, $\mathrm{ED}=0 \mathrm{~mm}$ and angulation $=0^{\circ}$ ), differentiated in the blue and violet wavelength ranges; output mode: flash mode 3-s.

Figure 6: FTIR spectra of the uncured materials FC2 (red) and TEVO-BF (blue).

Figure 7: Degree of conversion (DC) measured $300 \mathrm{~s}$ post light irradiation as a function of material, specimen depth and curing mode.

Figure 8: Degree of conversion (mean values, $n=6$ ) variation in time (up to $300 \mathrm{~s}$ ) as a function of RBC and specimen depth; left) TEVO-BF; right) FC2.

Figure 9: Weibull plot of the FS data as a function of material and curing mode.

Figure 10: Variation in mechanical properties (HV, DOC and $\mathrm{Y}_{\mathrm{HU}}$ ) with depth as a function of the curing conditions in the RAFT polymerised RBC (FC2).

Figure 11: Variation in mechanical properties (HV, DOC and $\left.\mathrm{Y}_{\mathrm{HU}}\right)$ with depth as a function of $\mathrm{RBC}$ at identical curing conditions (10 s, program high).

\section{Supplementary Data}

Figure S1: Spatial distribution of the parameters $\mathrm{HV}$ and $\mathrm{Y}_{\mathrm{HU}}$ as a function of the curing conditions in the RAFT polymerised RBC.

FigureS2: Spatial distribution of the parameters $\mathrm{HV}$ and $\mathrm{Y}_{\mathrm{HU}}$ as a function of $\mathrm{RBC}$ at identical curing conditions (10 s, program high).

Figure S3: Spatial distribution of the parameters $\mathrm{HV}$ and $\mathrm{Y}_{\mathrm{HU}}$ in the RAFT polymerized $\mathrm{RBC}(3 \mathrm{~s}$ flash): simulation of increasing exposure distance.

Figure S4: Spatial distribution of the parameters HV and $\mathrm{Y}_{\mathrm{HU}}$ in the RAFT polymerized $\mathrm{RBC}$ ( $3 \mathrm{~s}$ flash): simulation of angulation at $5 \mathrm{~mm}$ exposure distance.

Table S1: Variation in mechanical properties (HV and $\mathrm{Y}_{\mathrm{HU}}$ ) with depth as a function of RBC and curing conditions (Mean and standard deviation is indicated) 


\section{References}

1. Rueggeberg FA. State-of-the-art: dental photocuring--a review. Dent Mater, 2011; 27:39-52.

2. Deb S, Sehmi H. A comparative study of the properties of dental resin composites polymerized with plasma and halogen light. Dent Mater, 2003; 19:517-22.

3. Kim JW, Jang KT, Lee SH, Kim CC, Hahn SH, Garcia-Godoy F. Effect of curing method and curing time on the microhardness and wear of pit and fissure sealants. Dent Mater, 2002; 18:120-7.

4. Musanje L, Darvell BW. Polymerization of resin composite restorative materials: exposure reciprocity. Dent Mater, 2003; 19:531-41.

5. Musanje L, Darvell BW. Curing-light attenuation in filled-resin restorative materials. Dent Mater, 2006; 22:804-17.

6. Wydra J, Cramer N, Stansbury J, Bowman C. The reciprocity law concerning light dose-relationships applied to BisGMA/TEGDMA photopolymers: theoretical analysis and experimental characterization. Dent Mater 2014; 30:605-12.

7. Palagummia SV, Hong T, Wang Z, Moon CK, Chiang MYM. Resin viscosity determines the condition for a valid exposure reciprocity law in dental composites. Dent Mater 2020; 36(2): 310-319.

8. Leprince J, Devaux J, Mullier T, Vreven J, Leloup G. Pulpal-temperature rise and polymerization efficiency of LED curing lights. Oper Dent, 2010; 35:220-30.

9. Ilie N, Felten K, Trixner K, Hickel R, Kunzelmann KH. Shrinkage behavior of a resin-based composite irradiated with modern curing units. Dent Mater, 2005; 21:4839.

10. Sirovica S, M. S, Podgorski M, Thompson P, Palin W, Guo Y, et al. Structural Evidence That the Polymerization Rate Dictates Order and Intrinsic Strain Generation in Photocured Methacrylate Biomedical Polymers. Macromolecules, 2019; 52:5377-88.

11. Kutuk ZB, Gurgan S, Hickel R, Ilie N. Influence of extremely high irradiances on the micromechanical properties of a nano hybrid resin based composite. Am J Dent, 2017; 30:9-15.

12. Randolph LD, Palin WM, Watts DC, Genet M, Devaux J, Leloup G, et al. The effect of ultra-fast photopolymerisation of experimental composites on shrinkage stress, network formation and pulpal temperature rise. Dent Mater, 2014; 30:1280-9. 
13. Joly GD, Abuelyaman AS, Fornof AR, Craig BD, Krepski LR, Moser WH, et al., inventors: Dental compositions comprising addition-fragmentation agents (patent)2015.

14. Ilie N. Sufficiency of curing in high-viscosity bulk-fill resin composites with enhanced opacity. Clin Oral Investig, 2018; 23:747-55.

15. Watts DC, Amer O, Combe EC. Characteristics of visible-light-activated composite systems. British Dental Journal, 1984; 156:209-15.

16. Barner-Kowollik C. Handbook of RAFT Polymerization. Barner-Kowollik C, editor: WILEY-VCH Verlag GmbH \& Co. KGaA; 2008.

17. Todd J.2 Scientific Documentation 3s PowerCure.- Schaan-, Lieechtenstein Ivoclar Vivadent AG, 2019:[78 p.].

18. Gorsche C, Griesser M, Gescheidt G, Moszner N, Liska R. $\beta$-Allyl Sulfones as Addition-Fragmentation Chain Transfer Reagents: A Tool for Adjusting Thermal and Mechanical Properties of Dimethacrylate Networks. Macromolecules, 2014; 47:732736.

19. Todd J, Wanner- M. Scientific Documentation Tetric EvoCeram ${ }^{\circledR}$ Bulk Fill Schaan, Liechtenstein: Ivoclar Vivadent AG, Research \& Development 2014[42]. 


\section{Tables}

Table 1: Polymerisation kinetic parameters: $95 \%$ confidence interval of the modulation factors of the exponential function $(\mathrm{a}, \mathrm{b}, \mathrm{c}, \mathrm{d})$ and correlation factor $\left(\mathrm{R}^{2}\right)$.

\begin{tabular}{||l|c|c|c|c|c|c|c|}
\hline \multirow{2}{*}{ RBC } & Curing mode & $\begin{array}{c}\text { Widticknessh } \\
\mathrm{mm}\end{array}$ & $\mathrm{a}$ & $\mathrm{b}$ & $\mathrm{c}$ & $\mathrm{d}$ & $\underline{\mathrm{R}^{2}}$ \\
\hline \multirow{2}{*}{ TEVO-BF } & High, 10 s & 2 & $37.31 \div 38.80$ & $0.12 \div 0.13$ & $5.50 \div 8.22$ & $0.001 \div 0.01$ & $\underline{0.93}$ \\
\cline { 3 - 8 } & & 4 & $36.33 \div 37.89$ & $0.10 \div 0.12$ & $7.24 \div 11.31$ & $0.001 \div 0.01$ & $\underline{0.94}$ \\
\hline \multirow{3}{*}{ FC2 } & High, 10 s & 2 & $39.03 \div 40.25$ & $0.16 \div 0.18$ & $5.57 \div 6.85$ & $0.001 \div 0.01$ & $\underline{0.93}$ \\
\cline { 2 - 8 } & & 4 & $36.41 \div 38.27$ & $0.12 \div 0.14$ & $6.34 \div 7.71$ & $0.001 \div 0.01$ & $\underline{0.92}$ \\
\cline { 2 - 8 } & \multirow{2}{*}{ Flash, 3 s } & 2 & $36.18 \div 37.49$ & $0.21 \div 0.24$ & $7.48 \div 8.81$ & $0.01 \div 0.01$ & $\underline{0.90}$ \\
\cline { 3 - 8 } & & 4 & $37.11 \div 38.83$ & $0.15 \div 0.17$ & $7.52 \div 8.79$ & $0.01 \div 0.01$ & $\underline{0.91}$ \\
\hline
\end{tabular}

Table 2: Descriptive statistic (mean and standard deviation) for the flexural strength (FS, $\mathrm{MPa}$ ) and modulus (FM, GPa) as a function of material and curing mode. Superscripts indicate statistically homogeneous subgroups within a line (Tukey's HSD test, $\alpha=0.05$ ). Weibull parameters with the $95 \%$ confidence interval of the Weibull modulus $\mathrm{m}$ are indicated.

\begin{tabular}{|c|l|l|l|l|l|c|}
\hline RBC & Curing mode & \multicolumn{1}{c|}{ FS } & \multicolumn{1}{c|}{ FM } & $\mathrm{R}^{2}$ & \multicolumn{1}{c|}{$\mathrm{m}$} & $\sigma_{0}$ \\
\hline TEVO-BF & High, $10 \mathrm{~s}$ & $111.8 \pm 9.13(\mathrm{~A})$ & $6.7 \pm 0.81(\mathrm{~B})$ & 0.87 & $11.6 \div 16.6$ & 102.9 \\
\hline \multirow{2}{*}{ FC2 } & High, $10 \mathrm{~s}$ & $116.9 \pm 7.28(\mathrm{AB})$ & $6.0 \pm 0.66(\mathrm{~A})$ & 0.98 & $18.1 \div 20.7$ & 120.4 \\
\cline { 2 - 7 } & Flash, 3s & $119.5 \pm 8.76(\mathrm{~B})$ & $6.3 \pm 0.84(\mathrm{AB})$ & 0.96 & $14.4 \div 17.6$ & 123.5 \\
\hline
\end{tabular}




\section{Figures}

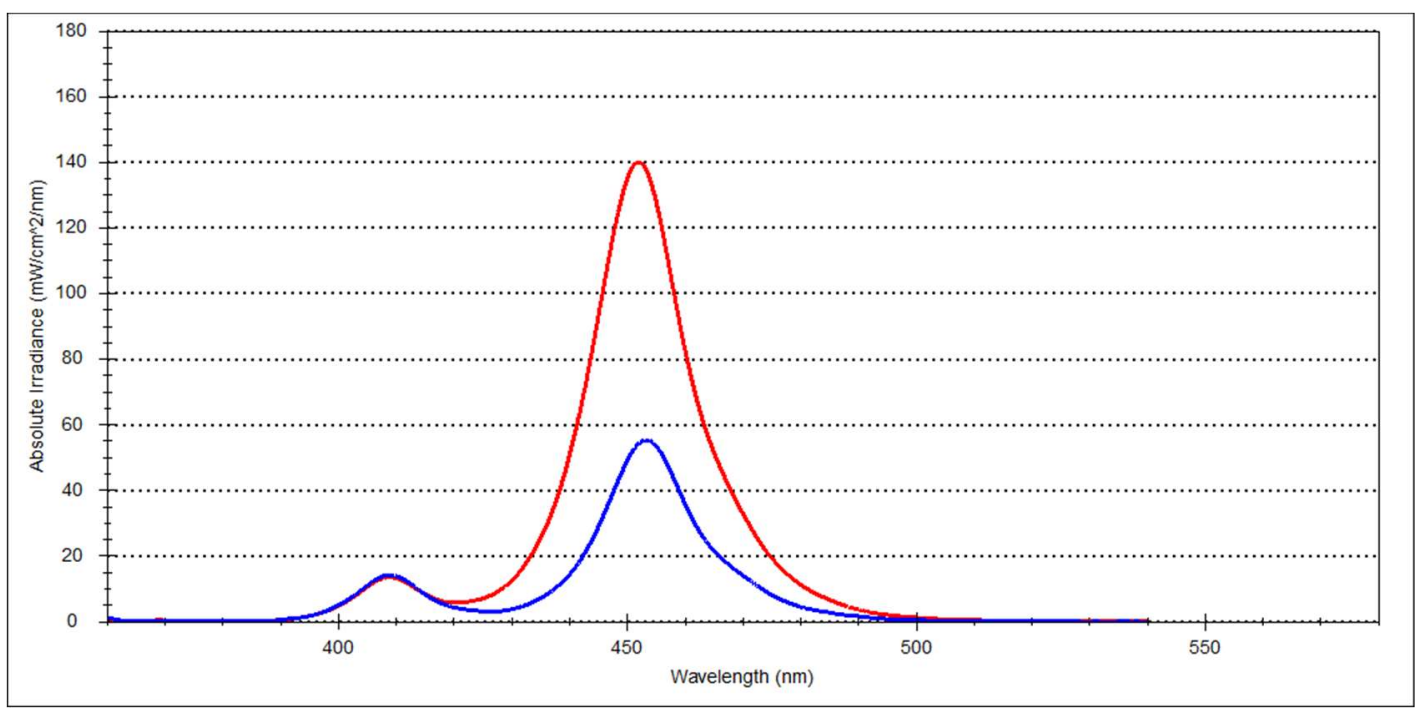

Fig 1: Spectral emission of the LED prototype light-curing unit measured in the modes: flash (red) and high (blue). Note that the spectral emission in the violet wavelength range was similar for both output modes.

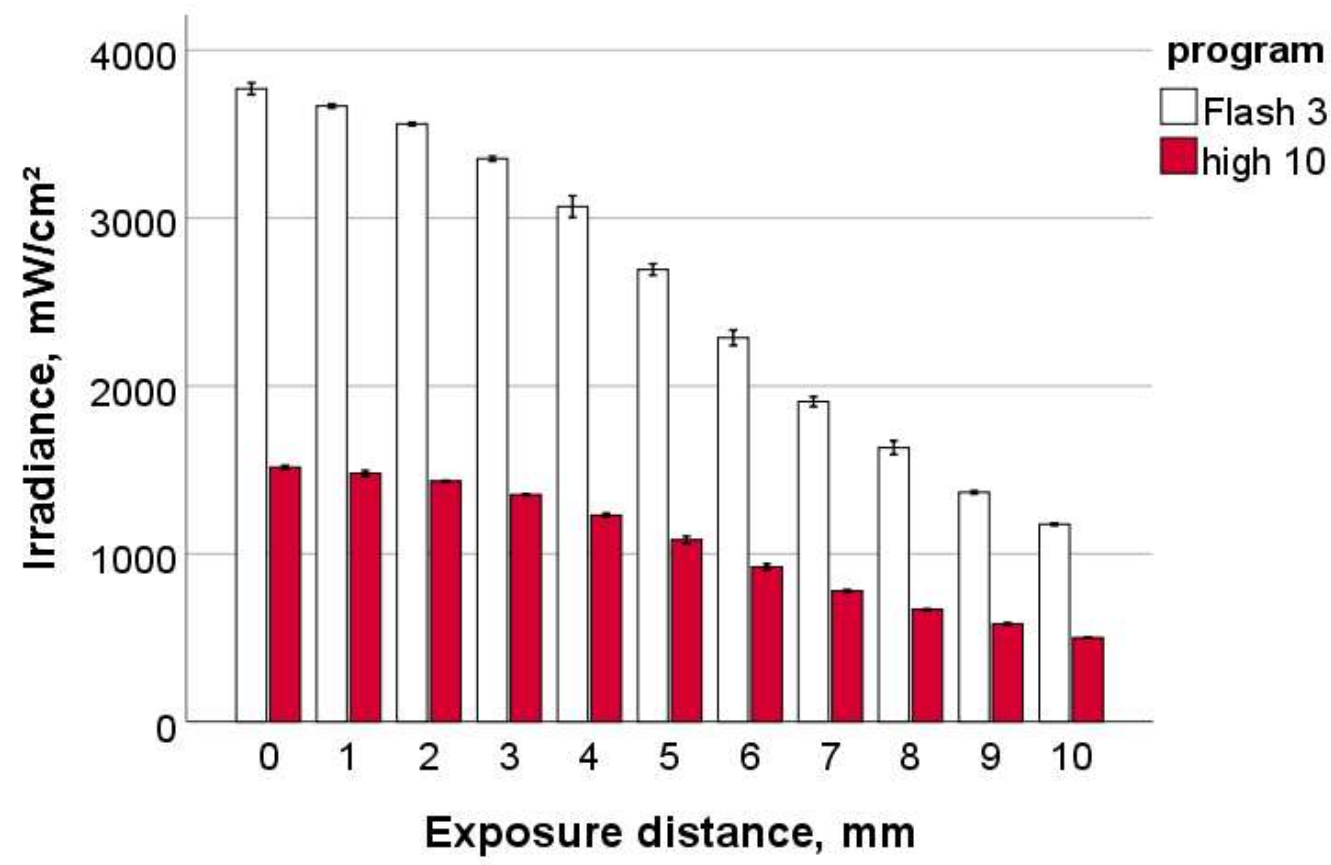

Fig 2: Variation in irradiance with exposure distance and curing mode. 

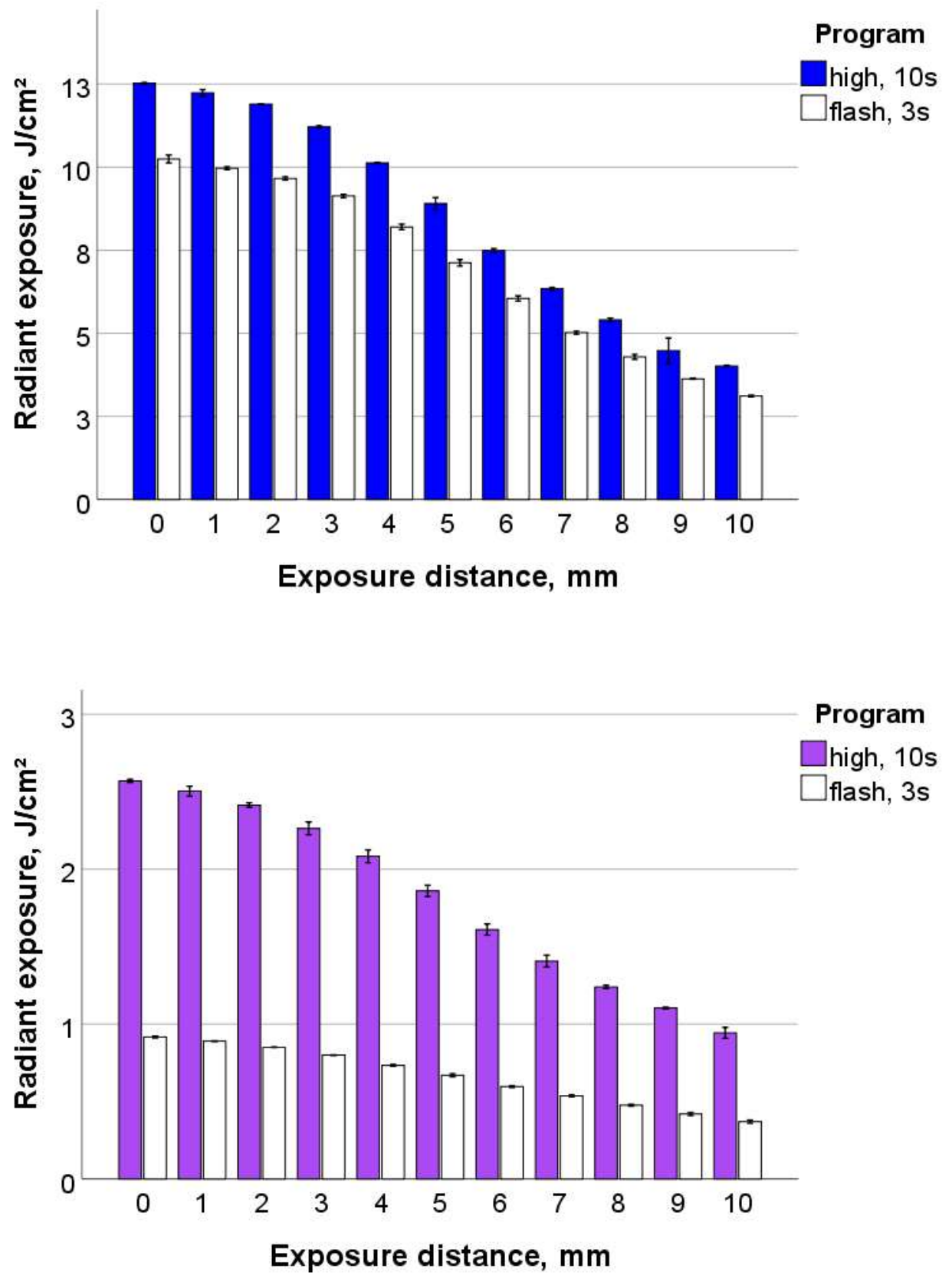

Fig 3: Variation in radiant exposure with exposure distance and curing mode for a) the blue wavelength range and $b$ ) the violet wavelength range. 


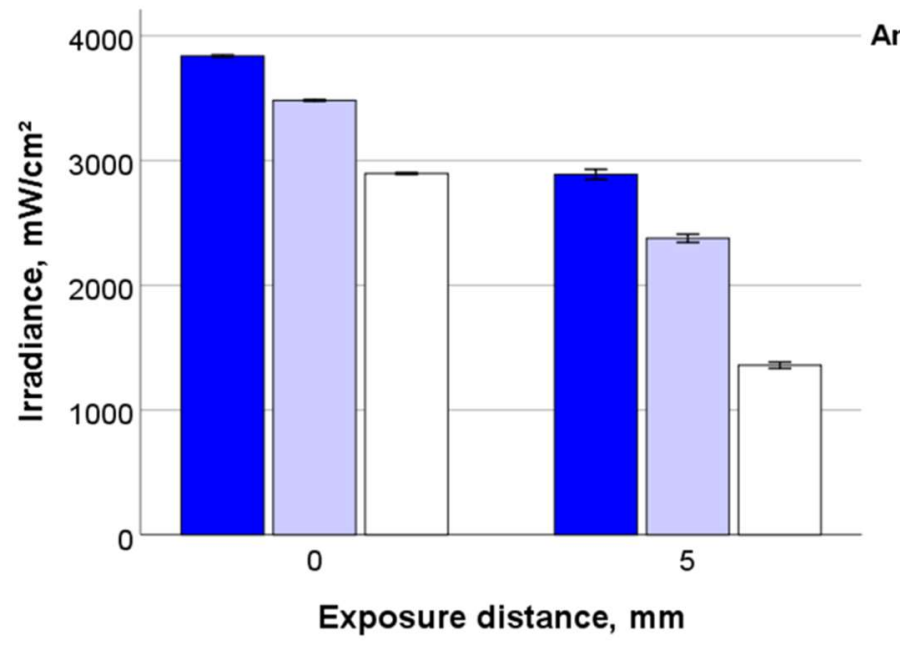

Angulation

$\square 0$

$\square 20$

$\square 30$
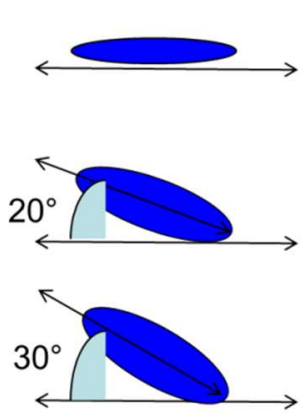

Fig 4: Variation in irradiance with the exposure distance and angulation (flash mode).

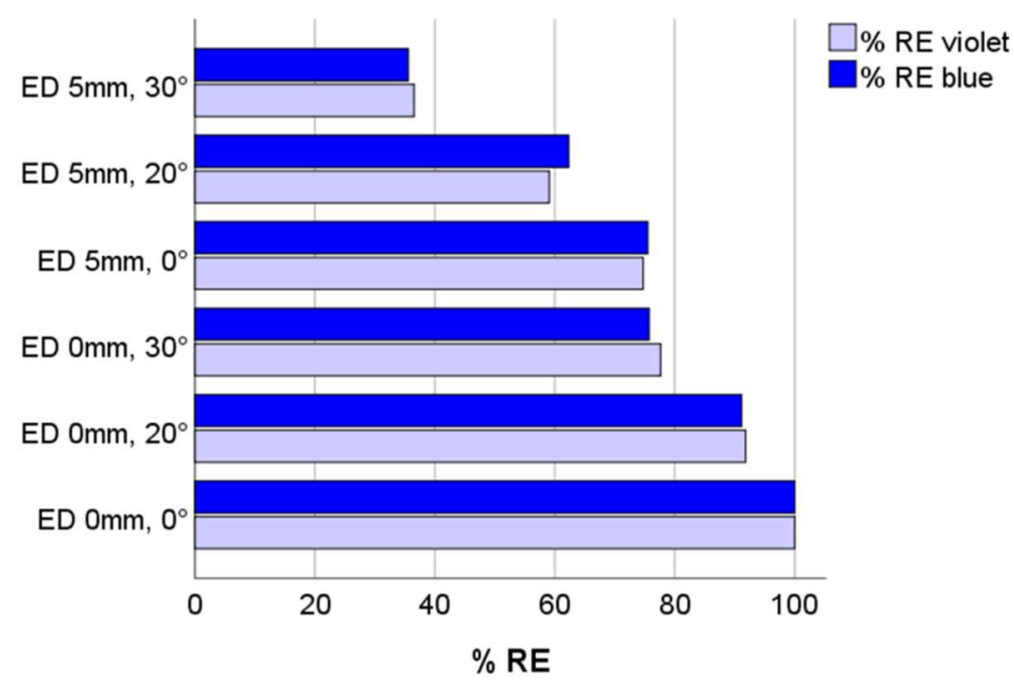

Fig 5: Percentage decrease in radiant exposure (RE) at simulated clinical relevant curing conditions in relation to the maximum RE-value, reached at ideal curing conditions (exposure distance, $\mathrm{ED}=0 \mathrm{~mm}$ and angulation $=0^{\circ}$ ), differentiated in the blue and violet wavelength ranges; output mode: flash mode 3 -s. 


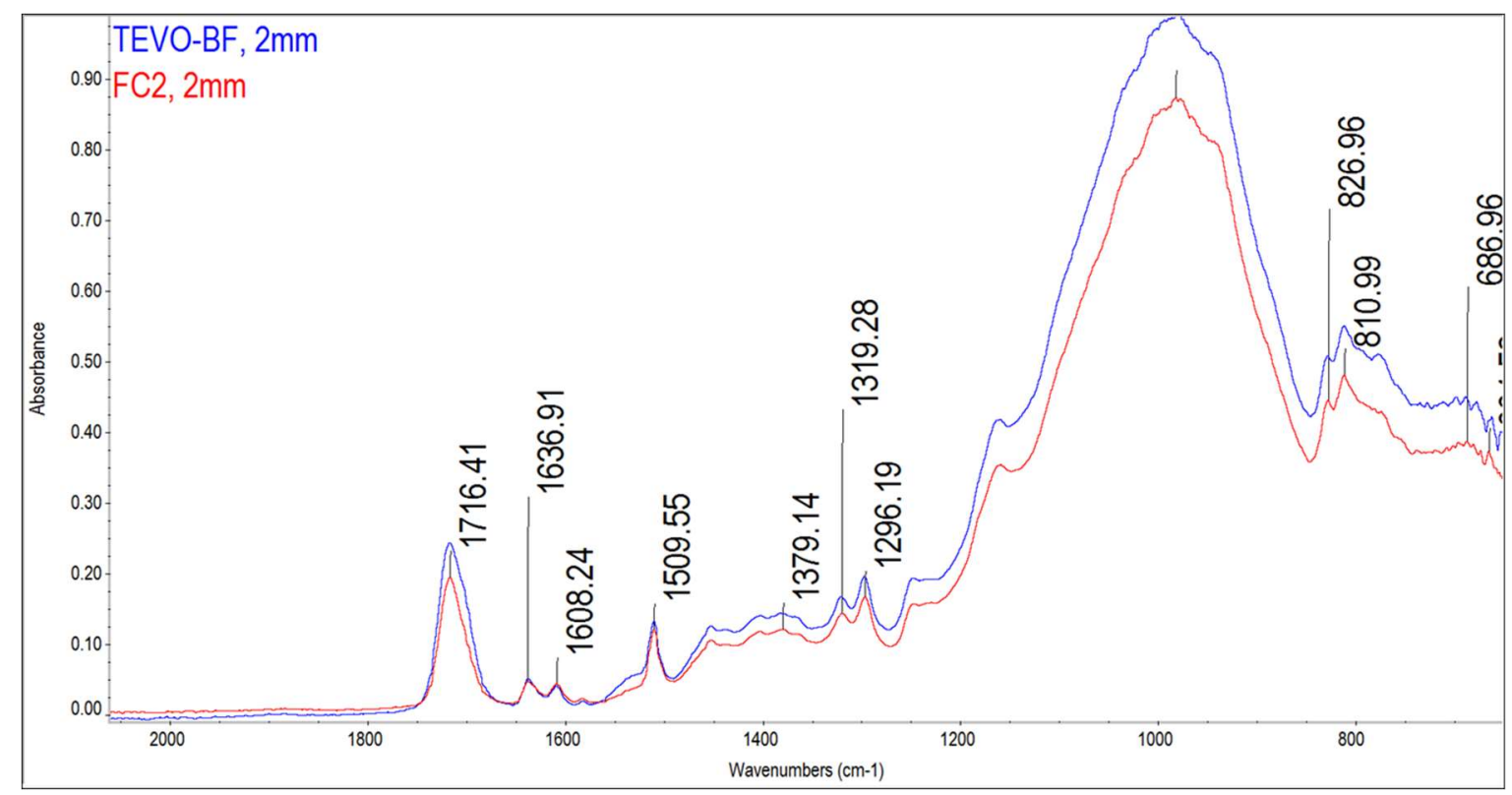

Fig 6: FTIR spectra of the uncured materials FC2 (red) and TEVO-BF (blue)

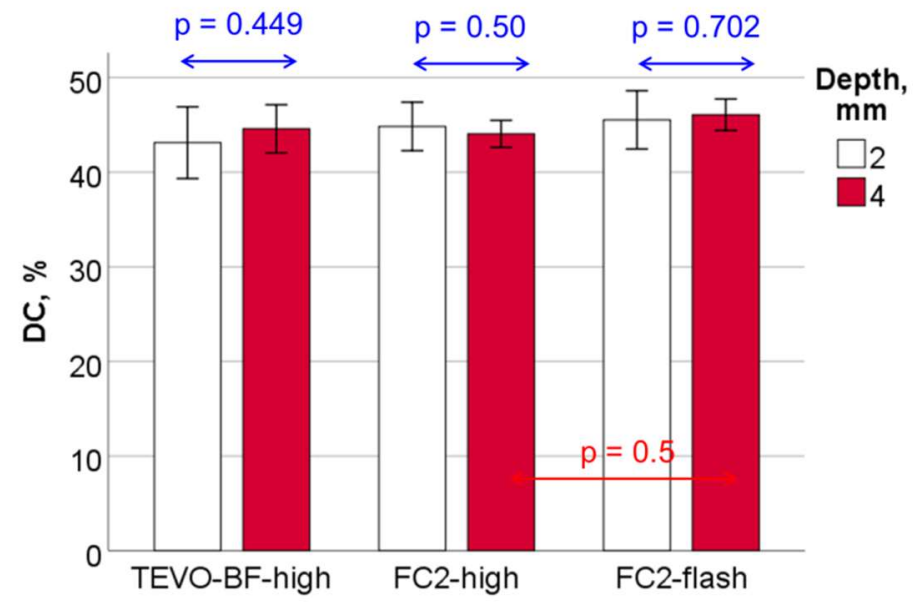

Fig 7: Degree of conversion (DC) measured $300 \mathrm{~s}$ post light irradiation as a function of material, specimen depth and curing mode 
TEVO-BF

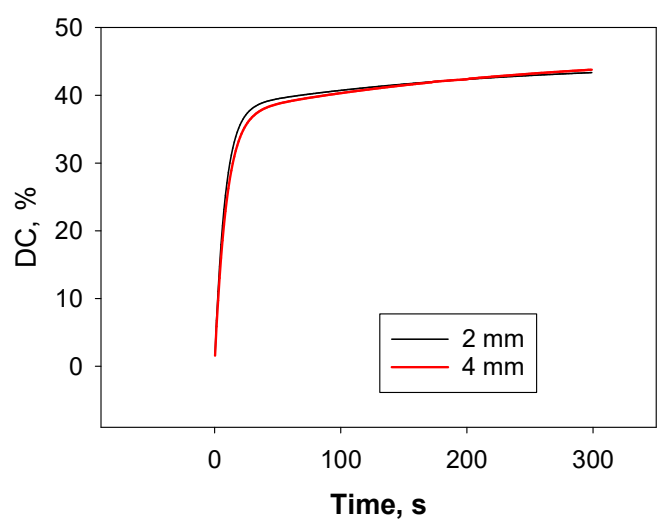

FC2

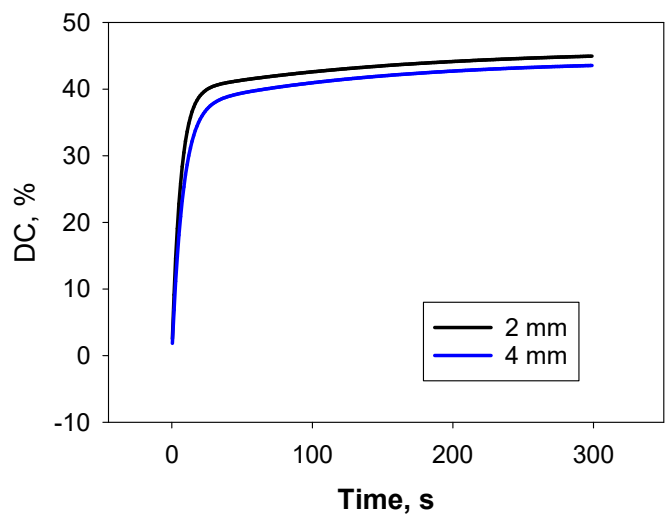

Fig 8: Degree of conversion (mean values, $\mathrm{n}=6$ ) variation in time (up to $300 \mathrm{~s}$ ) as a function of RBC and specimen depth; left) TEVO-BF; right) FC2

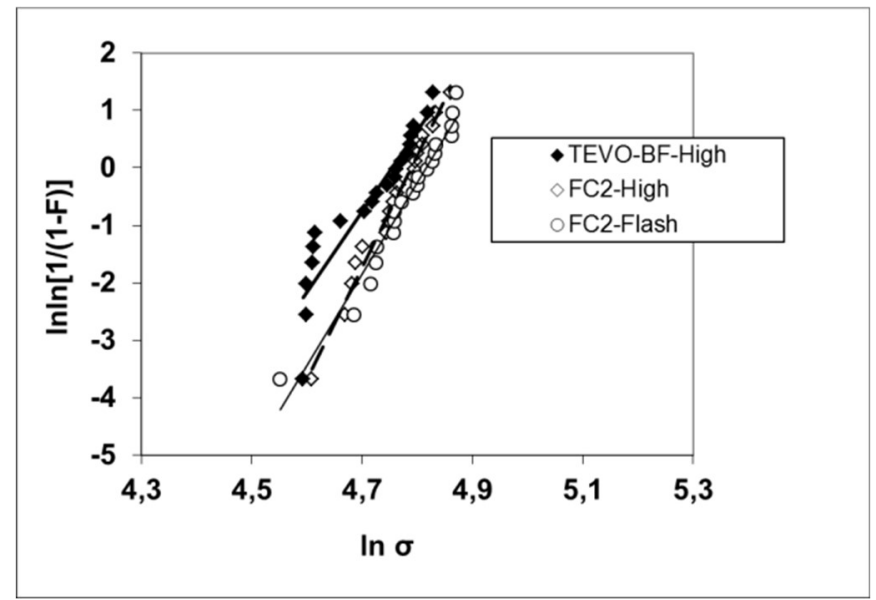

Fig 9: Weibull plot of the FS data as a function of material and curing mode. 

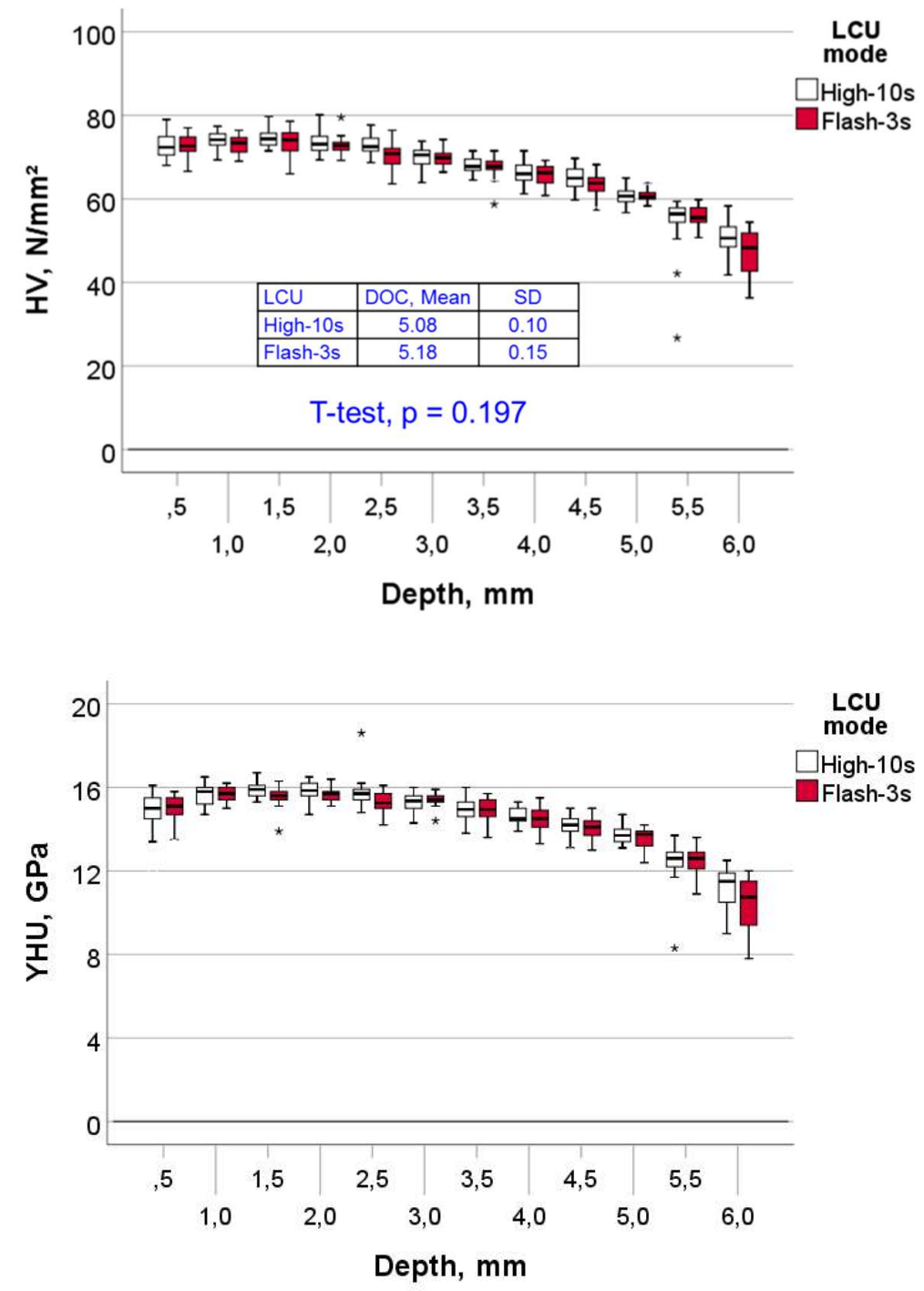

Fig 10: Variation in mechanical properties (HV, DOC and $\left.\mathrm{Y}_{\mathrm{HU}}\right)$ with depth as a function of the curing conditions in the RAFT polymerised RBC (FC2). Individual values are presented as supplementary material (Table S1) 

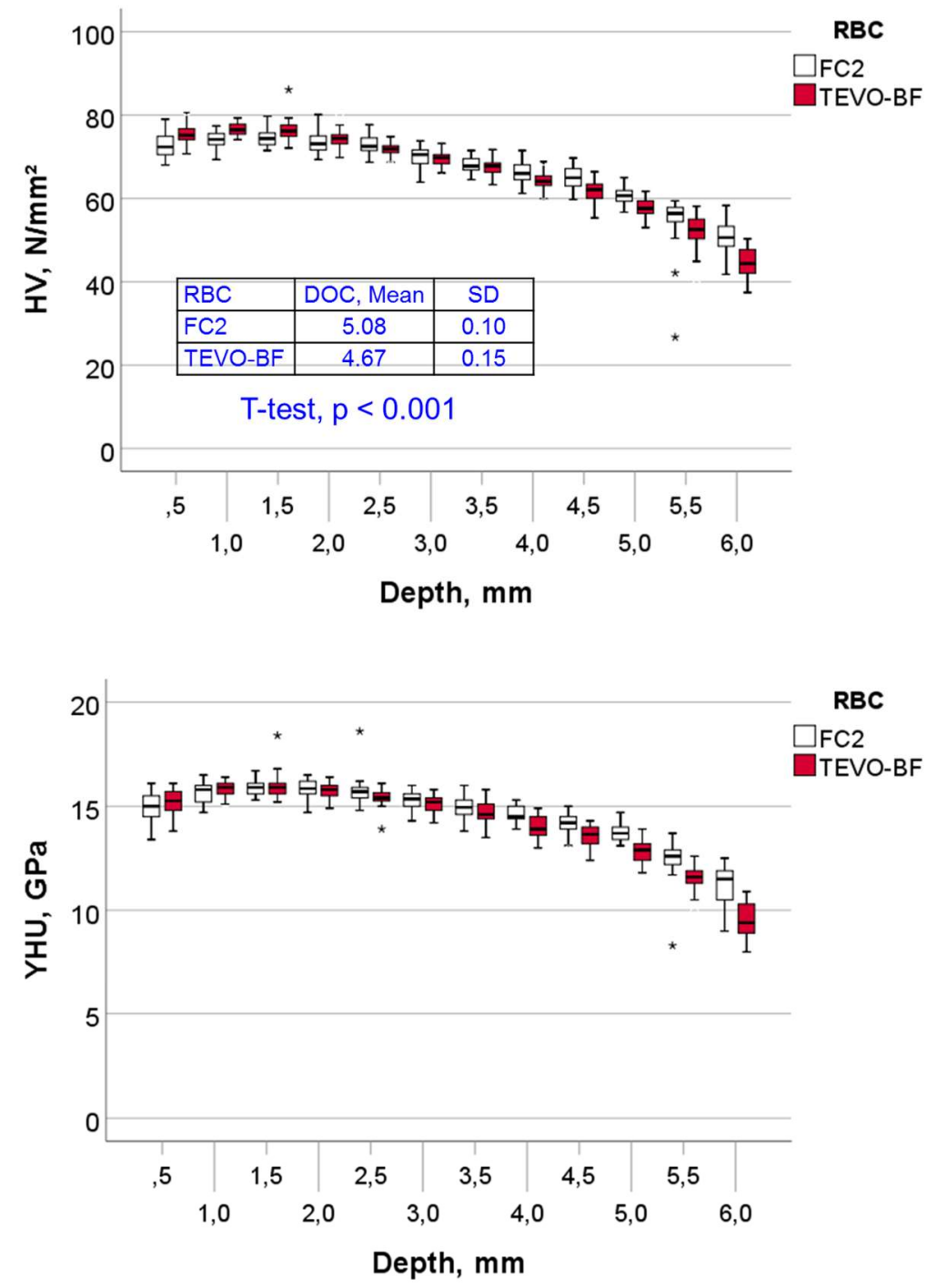

Fig 11: Variation in mechanical properties (HV, DOC and $\left.\mathrm{Y}_{\mathrm{HU}}\right)$ with depth as a function of $\mathrm{RBC}$ at identical curing conditions (10 s, program high) 


\section{Supplementary Data}

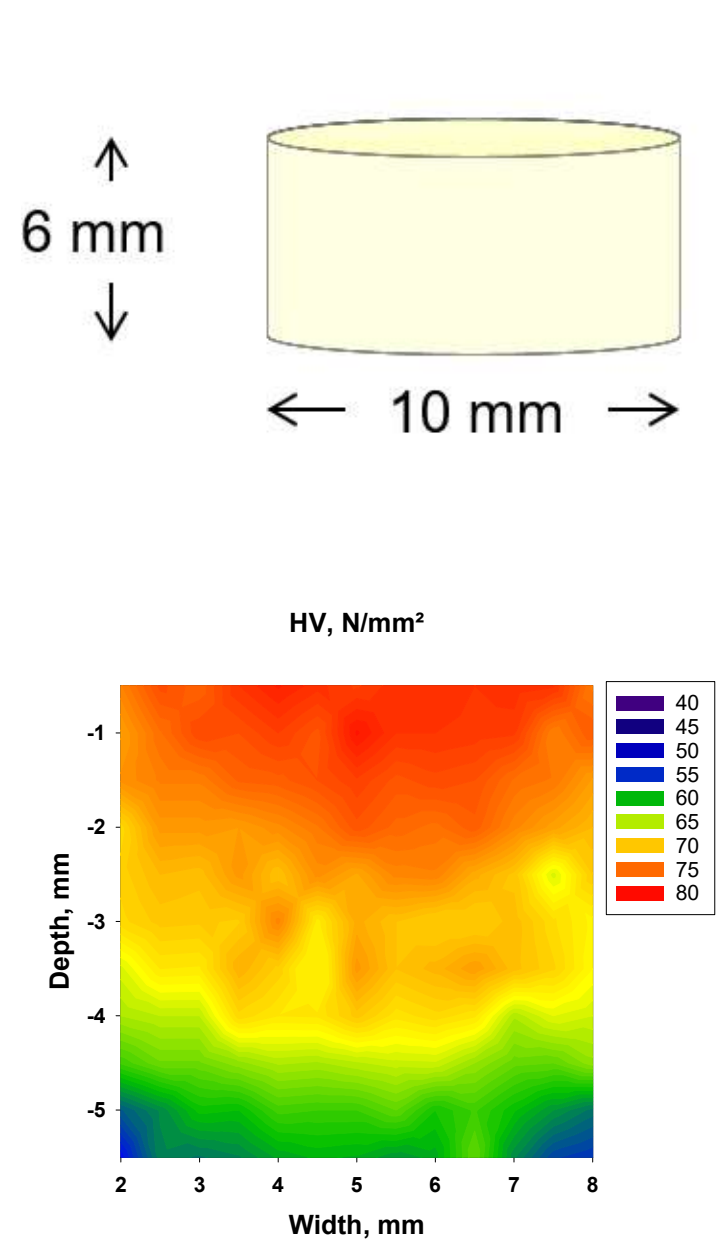

FC2-High, $10 \mathrm{~s}$

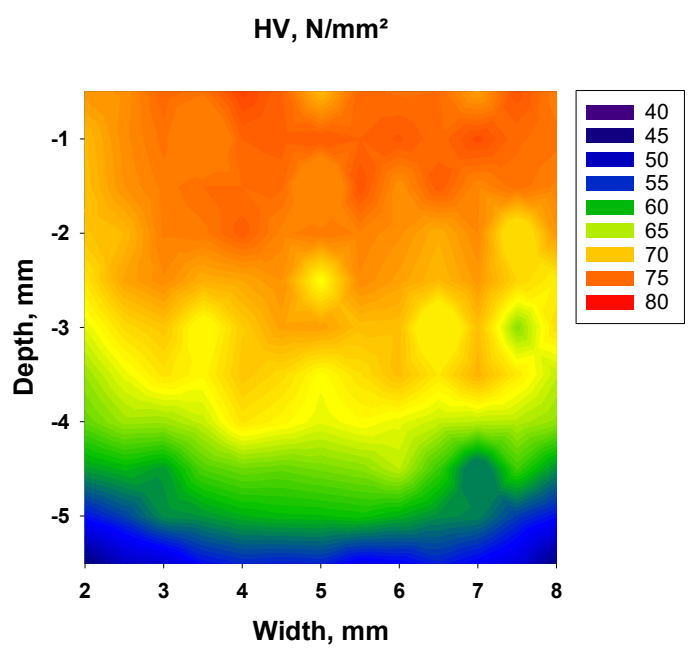

FC2-Flash, $3 \mathrm{~s}$
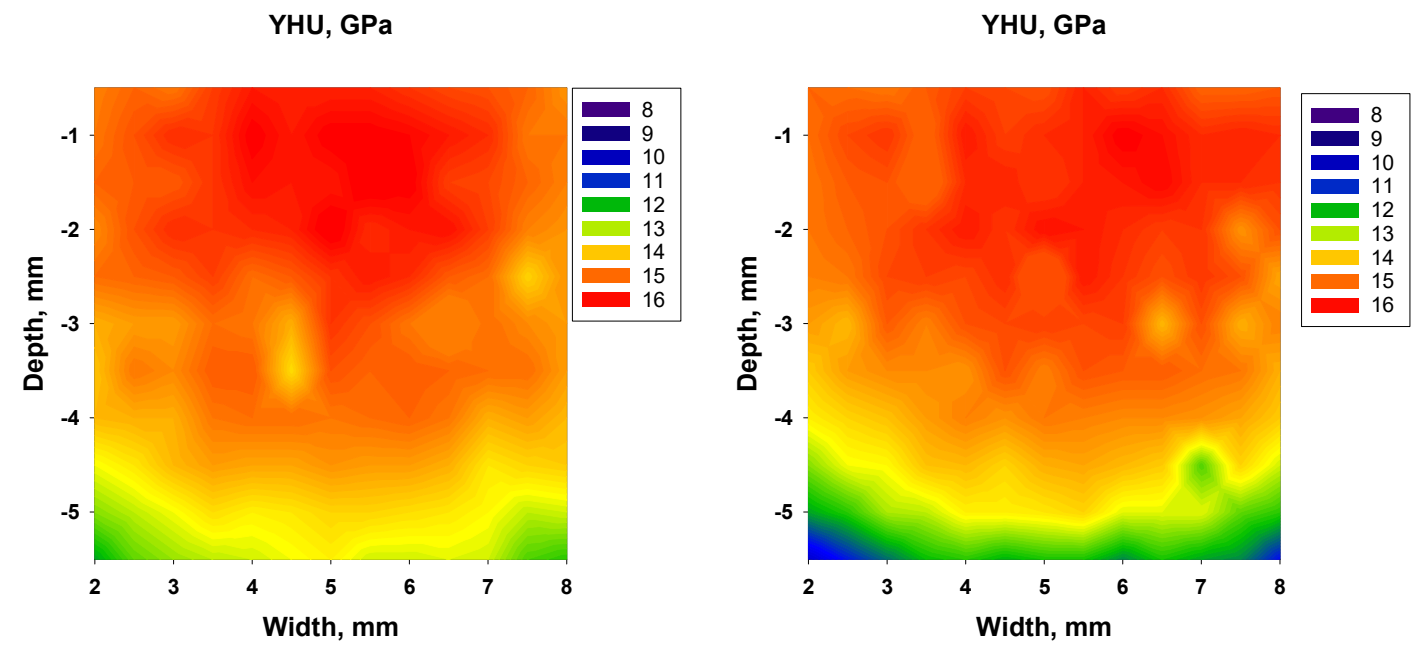

FC2-High, $10 \mathrm{~s}$

FC2-Flash, $3 \mathrm{~s}$ 
Fig S1: Spatial distribution of the parameters $\mathrm{HV}$ and $\mathrm{Y}_{\mathrm{HU}}$ as a function of the curing conditions in the RAFT polymerised RBC and schematic representation of the position of the depth-sensing indentations

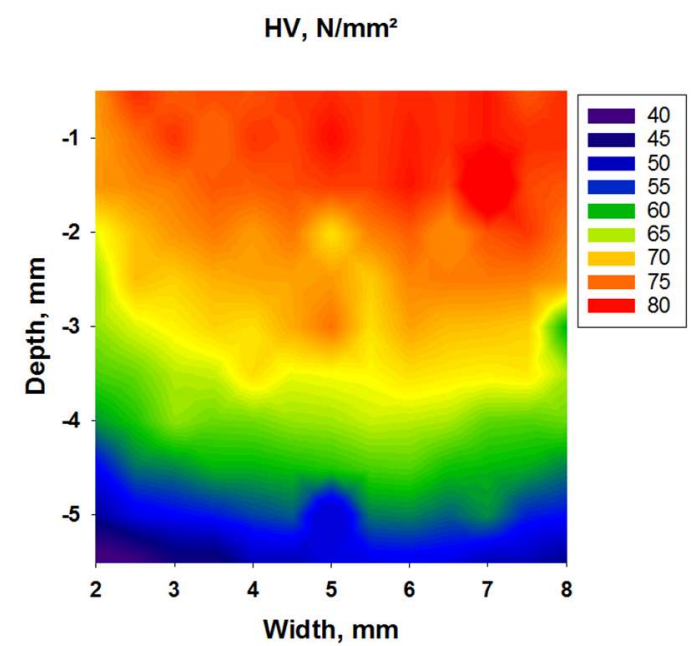

TEVO-BF-High, 10s

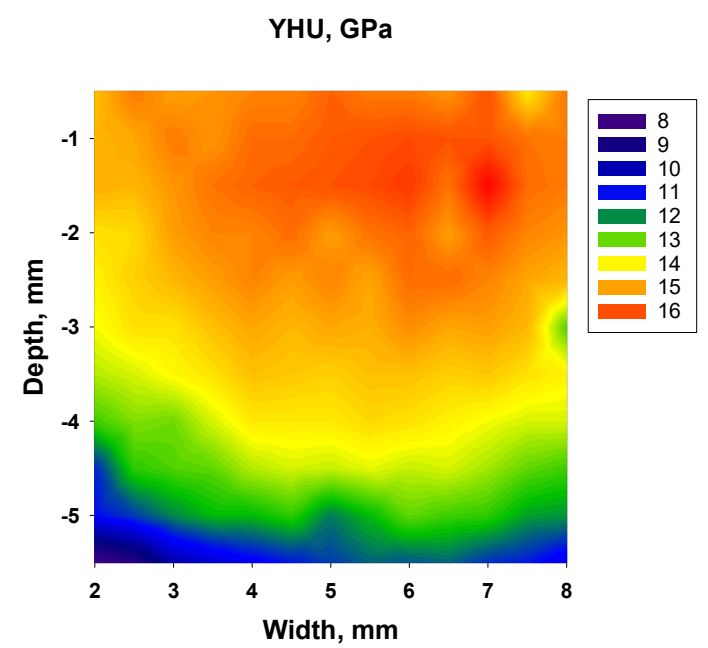

TEVO-BF-High, $10 \mathrm{~s}$

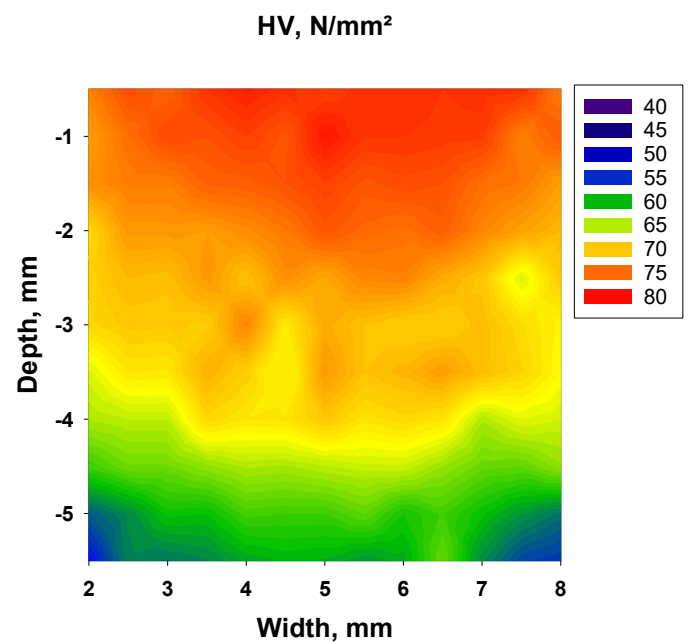

FC2-BF-High, 10s

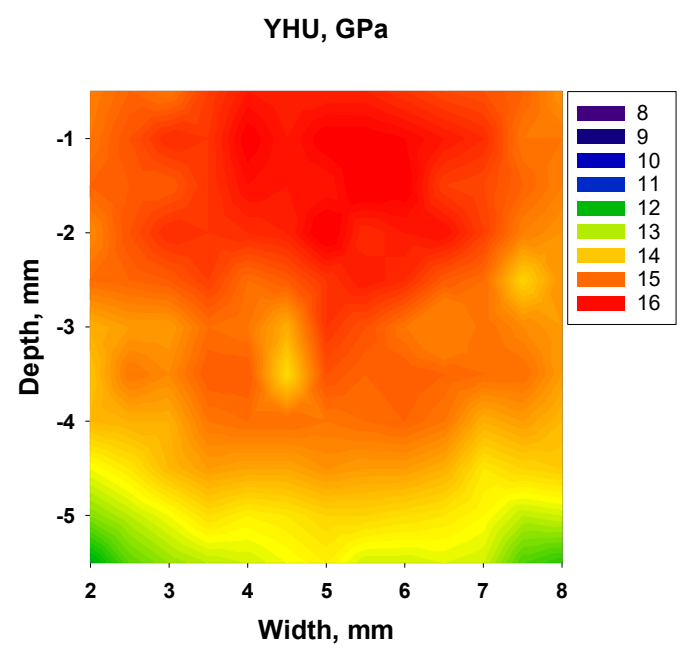

FC2-BF-High, $10 \mathrm{~s}$

Fig S2: Spatial distribution of the parameters $\mathrm{HV}$ and $\mathrm{Y}_{\mathrm{HU}}$ as a function of $\mathrm{RBC}$ at identical curing conditions (10 s, program high) 


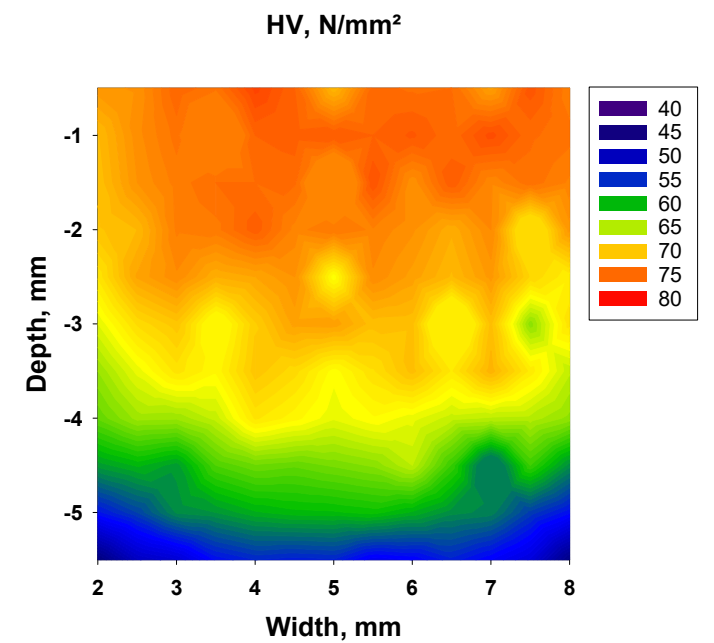

FC2-Flash, 3s, exposure distance $=0 \mathrm{~mm}$

YHU, GPa

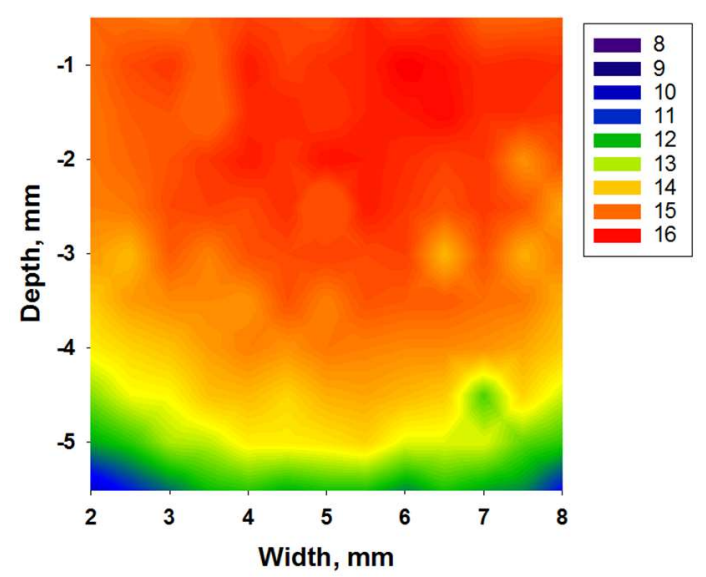

FC2-Flash, $3 \mathrm{~s}$, exposure distance $=0 \mathrm{~mm}$

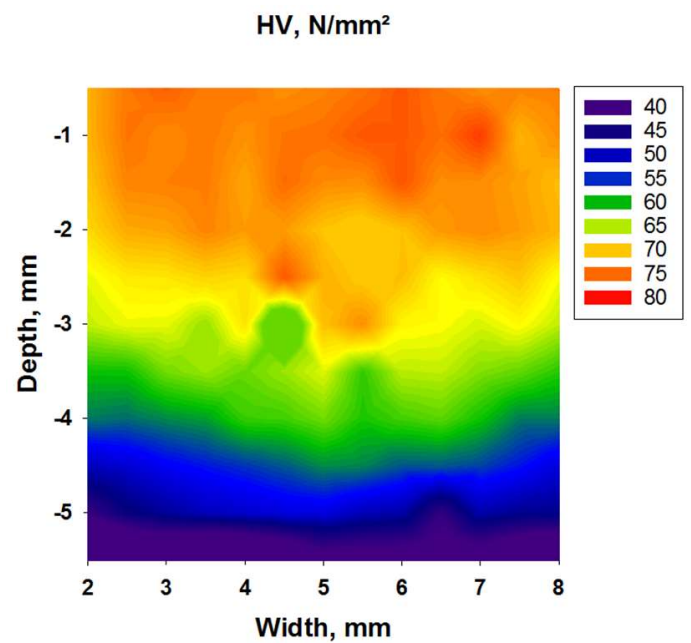

FC2-Flash, 3s, exposure distance $=5 \mathrm{~mm}$

YHU, GPa

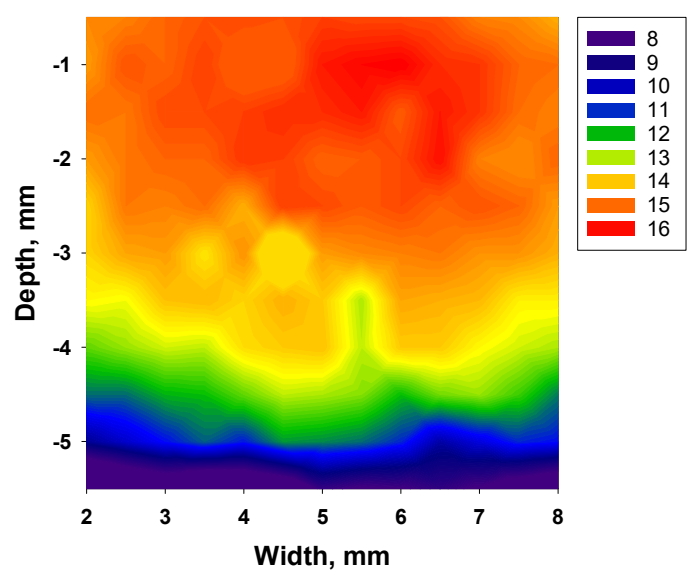

FC2-Flash, $3 \mathrm{~s}$, exposure distance $=5 \mathrm{~mm}$

Fig S3: Spatial distribution of the parameters HV and $\mathrm{Y}_{\mathrm{HU}}$ in the RAFT polymerized RBC (3 s flash): simulation of increasing exposure distance 
$\mathrm{HV}, \mathrm{N} / \mathrm{mm}^{2}$

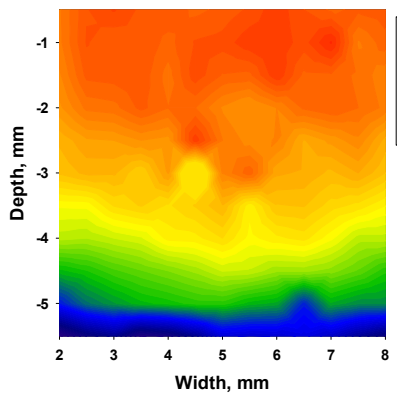

FC2-Flash, 3 s, exposure distance $5 \mathrm{~mm}$, Angulation $0^{\circ}$
$\mathrm{HV}, \mathrm{N} / \mathrm{mm}^{2}$

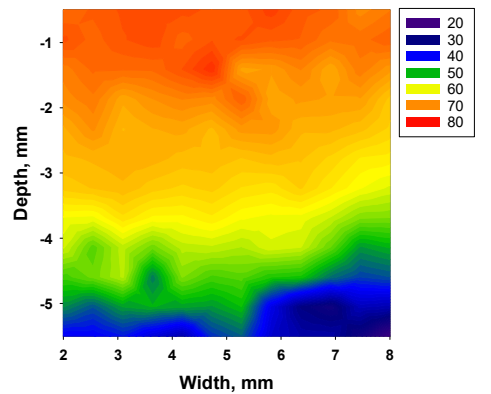

FC2-Flash, $3 \mathrm{~s}$, exposure distance $5 \mathrm{~mm}$, Angulation $20^{\circ}$
$\mathrm{HV}, \mathrm{N} / \mathrm{mm}^{2}$

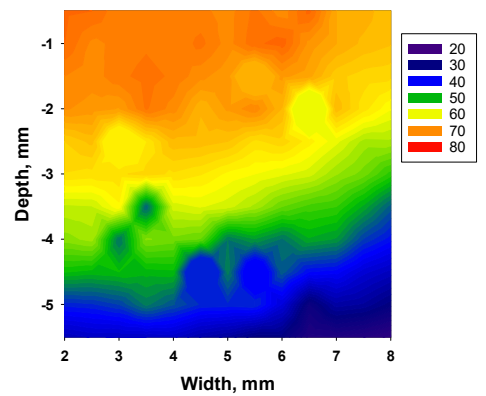

FC2-Flash, 3 s, exposure

distance $5 \mathrm{~mm}$, Angulation $30^{\circ}$
YHU, GPa

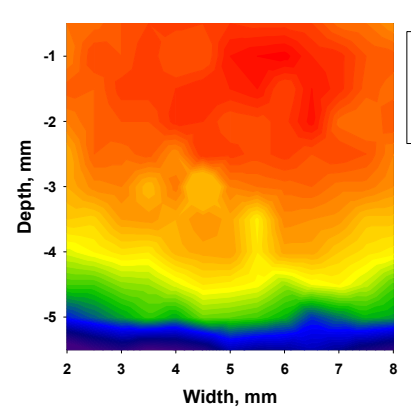

FC2-Flash, $3 \mathrm{~s}$, exposure distance $5 \mathrm{~mm}$, Angulation $0^{\circ}$
YHU, GPa

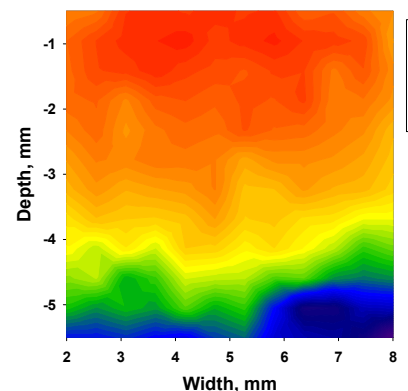

FC2-Flash, 3 s, exposure distance $5 \mathrm{~mm}$, Angulation $20^{\circ}$
YHU, GPa

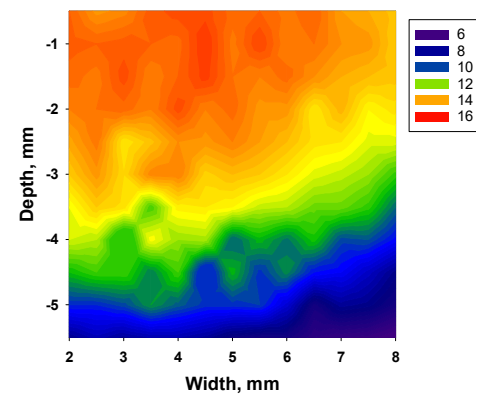

FC2-Flash, 3 s, exposure distance $5 \mathrm{~mm}$, Angulation $30^{\circ}$

Fig S4: Spatial distribution of the parameters $\mathrm{HV}$ and $\mathrm{Y}_{\mathrm{HU}}$ in the RAFT polymerized $\mathrm{RBC}$ ( $3 \mathrm{~s}$ flash): simulation of angulation at $5 \mathrm{~mm}$ exposure distance

Table S1: Variation in mechanical properties (HV and $\mathrm{Y}_{\mathrm{HU}}$ ) with depth as a function of RBC and curing conditions (Mean and standard deviation is indicated)

TEVO-BF (high- 10s)

\begin{tabular}{|c|c|c|c|c|}
\hline & \multicolumn{2}{|c|}{$\mathrm{HV}, \mathrm{N} / \mathrm{mm}^{2}$} & \multicolumn{2}{c|}{$\mathrm{Y}_{\mathrm{HU}}, \mathrm{GPa}$} \\
\hline $\begin{array}{l}\text { Depth, } \\
\mathrm{mm}\end{array}$ & $\mathrm{M}$ & $\mathrm{SD}$ & $\mathrm{M}$ & $\mathrm{SD}$ \\
\hline .5 & 75.2 & 3.1 & 15.2 & 0.7 \\
\hline 1.0 & 76.7 & 1.8 & 15.8 & 0.4 \\
\hline 1.5 & 76.4 & 2.7 & 15.9 & 0.6 \\
\hline 2.0 & 74.4 & 2.1 & 15.7 & 0.3 \\
\hline 2.5 & 71.7 & 1.7 & 15.4 & 0.4 \\
\hline 3.0 & 69.1 & 2.5 & 15.0 & 0.5 \\
\hline 3.5 & 67.5 & 1.7 & 14.7 & 0.5 \\
\hline 4.0 & 64.1 & 2.5 & 14.0 & 0.5 \\
\hline 4.5 & 61.4 & 2.9 & 13.5 & 0.6 \\
\hline
\end{tabular}




\begin{tabular}{|c|c|c|c|c|}
5.0 & 57.6 & 2.3 & 12.8 & 0.5 \\
\hline 5.5 & 52.0 & 4.0 & 11.6 & 0.7 \\
\hline 6.0 & 44.5 & 3.8 & 9.5 & 0.9 \\
\hline
\end{tabular}

FC2 (high- 10s)

\begin{tabular}{|c|c|c|c|c|}
\hline & \multicolumn{2}{|c|}{$\mathrm{HV}, \mathrm{N} / \mathrm{mm}^{2}$} & \multicolumn{2}{c|}{$\mathrm{Y}_{\mathrm{HU}}, \mathrm{GPa}$} \\
\hline $\begin{array}{c}\text { Depth. } \\
\text { mm }\end{array}$ & $\mathrm{M}$ & $\mathrm{SD}$ & $\mathrm{M}$ & $\mathrm{SD}$ \\
\hline .5 & 72.6 & 3.4 & 14.9 & 0.9 \\
\hline 1.0 & 74.1 & 2.0 & 15.7 & 0.5 \\
\hline 1.5 & 74.3 & 2.0 & 15.9 & 0.3 \\
\hline 2.0 & 73.5 & 2.4 & 15.8 & 0.4 \\
\hline 2.5 & 72.9 & 3.1 & 15.7 & 0.7 \\
\hline 3.0 & 70.1 & 2.2 & 15.3 & 0.4 \\
\hline 3.5 & 68.1 & 2.3 & 14.9 & 0.6 \\
\hline 4.0 & 66.1 & 2.4 & 14.6 & 0.4 \\
\hline 4.5 & 64.9 & 2.7 & 14.1 & 0.6 \\
\hline 5.0 & 60.8 & 2.3 & 13.7 & 0.5 \\
\hline 5.5 & 54.8 & 6.3 & 12.4 & 1.0 \\
\hline 6.0 & 50.7 & 4.2 & 11.1 & 1.1 \\
\hline
\end{tabular}

FC2 (flash. 3s)

\begin{tabular}{|c|c|c|c|c|}
\hline & \multicolumn{2}{|c|}{$\mathrm{HV}, \mathrm{N} / \mathrm{mm}^{2}$} & \multicolumn{2}{c|}{$\mathrm{Y}_{\mathrm{HU}}, \mathrm{GPa}$} \\
\hline $\begin{array}{c}\text { Depth. } \\
\mathrm{mm}\end{array}$ & $\mathrm{M}$ & $\mathrm{SD}$ & $\mathrm{M}$ & $\mathrm{SD}$ \\
\hline .5 & 72.6 & 3.0 & 15.0 & 0.7 \\
\hline 1.0 & 73.4 & 3.0 & 15.6 & 0.4 \\
\hline 1.5 & 73.5 & 2.8 & 15.6 & 0.5 \\
\hline 2.0 & 73.1 & 2.3 & 15.6 & 0.5 \\
\hline 2.5 & 70.2 & 2.9 & 15.3 & 0.6 \\
\hline 3.0 & 69.7 & 1.9 & 15.4 & 0.3 \\
\hline 3.5 & 67.5 & 2.5 & 14.9 & 0.6 \\
\hline 4.0 & 66.4 & 3.8 & 14.5 & 0.7 \\
\hline 4.5 & 63.2 & 2.6 & 14.0 & 0.6 \\
\hline 5.0 & 60.7 & 1.7 & 13.6 & 0.5 \\
\hline 5.5 & 55.6 & 2.6 & 12.5 & 0.7 \\
\hline 6.0 & 46.5 & 7.4 & 10.3 & 1.7 \\
\hline
\end{tabular}

